\title{
Article \\ Characterization of TSO and DSO Grid System Services and TSO-DSO Basic Coordination Mechanisms in the Current Decarbonization Context
}

\author{
Ricardo Silva *(D), Everton Alves (D), Ricardo Ferreira, José Villar (D) and Clara Gouveia (D) \\ INESC TEC-Institute for Systems and Computer Engineering, Technology and Science, \\ 4200-465 Porto, Portugal; everton.1.alves@inesctec.pt (E.A.); ricardo.j.ferreira@inesctec.pt (R.F.); \\ jose.villar@inesctec.pt (J.V.); clara.s.gouveia@inesctec.pt (C.G.) \\ * Correspondence: ricardo.emanuel@inesctec.pt; Tel.: +351-22-209-4230
}

check for updates

Citation: Silva, R.; Alves, E.; Ferreira,

R.; Villar, J.; Gouveia, C.

Characterization of TSO and DSO

Grid System Services and TSO-DSO

Basic Coordination Mechanisms in

the Current Decarbonization Context.

Energies 2021, 14, 4451. https://

doi.org/10.3390/en14154451

Academic Editors: Nicu Bizon,

Mihai Oproescu, Philippe Poure,

Rocío Pérez de Prado,

Abdessattar Abdelkefi and

Tomonobu Senjyu

Received: 27 May 2021

Accepted: 19 July 2021

Published: 23 July 2021

Publisher's Note: MDPI stays neutral with regard to jurisdictional claims in published maps and institutional affiliations.

Copyright: (c) 2021 by the authors. Licensee MDPI, Basel, Switzerland. This article is an open access article distributed under the terms and conditions of the Creative Commons Attribution (CC BY) license (https:// creativecommons.org/licenses/by/ $4.0 /$ )
Abstract: Power systems rely on ancillary services (ASs) to ensure system security and stability. Until recently, only the conventional power generation resources connected to the transmission grids were allowed to provide these ASs managed by the transmission system operators (TSOs), while distribution system operators (DSOs) had a more passive role, focused on guaranteeing distribution capacity to bring power to final consumers with enough quality. Now, with the decarbonization, digitalization and decentralization processes of the electrical networks, the growing integration of distributed energy resources (DERs) in distribution grids are displacing conventional generation and increasing the complexity of distribution networks' operation, requiring the implementation of new active and coordinated management strategies between TSOs and DSOs. In this context, DERs are becoming potential new sources of flexibility for both TSOs and DSOs in helping to manage the power system. This paper proposes a systematic characterization of both traditional and potentially new ASs for TSOs, and newly expected DSO local system services to support the new distribution grid operation paradigm, reviewing, in addition, the main TSO-DSO coordination mechanisms.

Keywords: TSO grid services; DSO grid services; congestions management; voltage control; distributed flexibility; TSO-DSO coordination

\section{Introduction}

Ancillary services (ASs) are grid services needed to support the transmission of electric power from the generators to the consumers at the distribution grids, to guarantee the continuity, quality and security of the supply. ASs, traditionally provided by conventional generation power plants connected to the transmission grid, have been mainly directed to the provision of system services to the transmission system operators (TSOs) for the operation of the transmission grid. Some ASs are mandatory and not remunerated, with requirements stipulated by network codes, while others are traded under market mechanisms.

The increase of non-dispatchable and less predictable distributed generation (DG) and the progressive decrease of conventional dispatchable generation is making the balance between supply and demand harder to achieve, which emphasizes the relevance of balancing ASs. At the same time, this is also transforming the distribution grids from passive to active grids by accommodating many of the new power system resources and increasing the operational complexity and responsibilities of distribution system operators (DSOs) [1]. Indeed, deregulation, decentralization and decarbonization of power systems, with the progressive closure of $\mathrm{CO}_{2}$-emitting power plants (the traditional providers of system services due to their high controllability), the increasing digitalization [2] and the integration of distributed energy resources (DERs) [3,4], demands: (a) the introduction of new system services to ensure the secure operation of an increasingly complex and distributed electrical system [5] and (b) the need for designing the appropriate market 
mechanisms to incentivize optimal private investment for an efficient provision of the services by integrating all kinds of resources [6].

As the presence of DER grows, so do the system needs for flexibility and system services to guarantee the secure energy supply, as well as the efficient integration of all new renewable energy sources (RES) into the system, including low-voltage (LV) resources at the consumers' level. However, DER can also become active players in local and wholesale energy electricity markets, local and system-wide AS markets and capacity markets, with the potential to promote the integration of distributed RES through the efficient and coordinated management of the available resources. DER can offer their flexibility in local and global markets, providing benefits to the distribution and transmission systems' operation, while increasing the revenue streams for the asset owners [7]. As a result, new actors and roles are entering in this new electricity market scene, such as aggregators (AGGs), flexibility providers (FPs) and balance responsible parties (BRPs), among others [8].

Traditional grid services for TSOs are for example reviewed in [9]. The work in [10] characterizes new DSO services, and makes an attempt to assess the amount of AS that distributed resources could provide to both TSOs and DSOs. Integration of DER to provide existing TSO ASs and investigation of new DSO local system services is also addressed in [11], where market designs for DER integration are also discussed. The international agency IRENA discuss [5] innovative TSO ASs and how DERs can be integrated as new AS providers, while in [1] the new paradigm of distribution grid operation with new market-base ASs to support the new roles of DSOs is addressed. Many research works and conceptual and commercial initiatives have also been proposed in recent projects. Their main objectives are improving DER integration as active FPs in local system services to support the distribution grids' operation, and, under TSO-DSO coordination schemes, contributing to the transmission grid operation through the DER participation in system-wide services. For example, EU-SysFlex [12] deals with the provision of TSO AS with distributed resources and with TSO-DSO coordination issues. EUniversal $[13,14]$ focus on DSO local system services and market mechanisms, and seeks to develop a universal interface to ease DER access to provide those services. Interconnect [15] has several tasks devoted to the provision of flexibility services to DSOs and the development of interoperable interfaces to smooth connectivity issues due to proprietary manufacturers standards. INTERRFACE [16] also deals with connectivity issues among TSO-DSO consumers by characterizing flexibility services and developing the corresponding interfaces, and OneNet [17] focuses on the development of interfaces to improve the integration of all actors, flexibility markets and platforms across Europe. Finally, ref. [8] provides an insightful revision of the best practices and the main obstacles (regulatory, technical and economic) of the deployment of demand side flexibility (DSF) on a national level in different European countries, with different sizes, locations, generation mixes and legislations and operational principles.

Based on existing literature and on the work of the previously mentioned projects (namely EU-SysFlex, Interconnect and EUniversal), this paper presents a characterization of current and expected TSO and DSO flexibility needs in the current decarbonization context, and the services that DER can provide to meet those needs. The main contributions are: (a) a characterization of the current and expected TSO services considering the power system evolution and expected scarcities; (b) a characterization of the potential future DSO system services, with the identification of the main attributes to specify their technical requirements and a DSOs' practical assessment on the needs and services identified; (c) a revision of the main TSO-DSO markets coordination mechanisms to integrate DER in the provision of system services. One of the motivations for this work was the fact that previous approaches did not provide such a formal, comprehensive and consistent review and vision on both TSO and DSO grid services, with a special focus on DSO services and on the flexibility markets structures for their acquisition. Indeed, these are concepts strongly linked but that are very often scattered in many different works and addressed separately. Therefore, this work fills an existing gap by providing a comprehensive reference for future 
works that could help further research on new strategies for flexibility services design, acquisition mechanisms and facilitating tools.

The structure of the paper is as follows. Section 2 describes the regulatory background and defines the main system and market actors involved in the flexibility provision processes. Section 3 describes the current and expected (due to the decarbonization path) TSO needs and services, while Section 4 focuses on the analysis of DSO needs and potential future services as one of the main topics addressed in this work. Section 5 reviews the main basic TSO-DSO coordination mechanisms, and lastly, Section 6 presents the conclusions and final remarks.

\section{Flexibility Provision Context}

\subsection{Regulatory Background}

In Europe, the use of flexibility from distribution networks was first established with Regulation 2017/1485, which defines a guideline on electricity transmission system operation [18] and provides "rules and responsibilities for the coordination and data exchange between TSOs, between TSOs and DSOs, and between TSOs or DSOs and SGUs (significant grid users), in operational planning and in close to real-time operation." In particular, article 182 establishes the guidelines for the prequalification and delivery of active power reserves by units or groups connected to the distribution system, which include service delivery information, timelines and coordination with the reserve, connecting DSOs and other possible intermediary DSOs.

More recently, in 2019, the European Commission proposed a new directive for the electricity markets, Directive 2019/944, promoting the active participation of consumers in the energy market, promoting electricity market competition and recognizing the role of AGGs as intermediaries between customers and the wholesale market. The Electricity Market Directive also defines the role of the DSO in the market and sets the requirements for its independence. In particular, Article 32 (Incentives for the use of flexibility in distribution networks) sets new requirements on the flexibility's use in distribution networks [19]. The required regulatory framework shall be provided by Member States in order to incentivize DSOs to procure flexibility services in the areas under their supervision. All customers should have access to electricity markets where they can trade their self-generated electricity and potential flexibility. However, the flexibility procurement must be, on the one hand, economically efficient, while on the other, it must not lead to market distortions or to the increase of grid congestions. Therefore, Member States must present network development plans for their distribution systems that account for the integration of RES installations, as well as promote the development of energy storage facilities and the electrification of the transport sector. Strategies such as demand response or energy efficiency and technologies such as energy storage or any other resources that can defer or eliminate the need for system expansions should also be included by the DSOs.

\subsection{Main Actors}

The necessary adaptation of market designs to allow DER participation requires defining new roles either played by new actors, such as AGGs or BRPs, or by extending the roles of parties that already exist, namely the TSOs and particularly the DSOs [8].

This section revises the roles of the actors related to system services and flexibility provision, considering the main interactions represented in Figure 1. Actors usually refer to real entities or parties (such as companies, market players, regulated entities and other related stakeholders) that participate in a business model under study. Roles represent the external intended behaviors of an actor. As such, actors can assume one or more roles. In this sense DSOs, TSOs or suppliers are actors that carry out their activities by performing roles [20]. While actors and roles are distinct concepts, they are sometimes hard to differentiate. In addition, joining them allows sometimes to provide simpler and closer-to-reality descriptions of existing or potential business models. For simplicity, the 
following definitions (based on the work carried out under the Interconnect Project [21]) are proposed and will be considered throughout the paper:

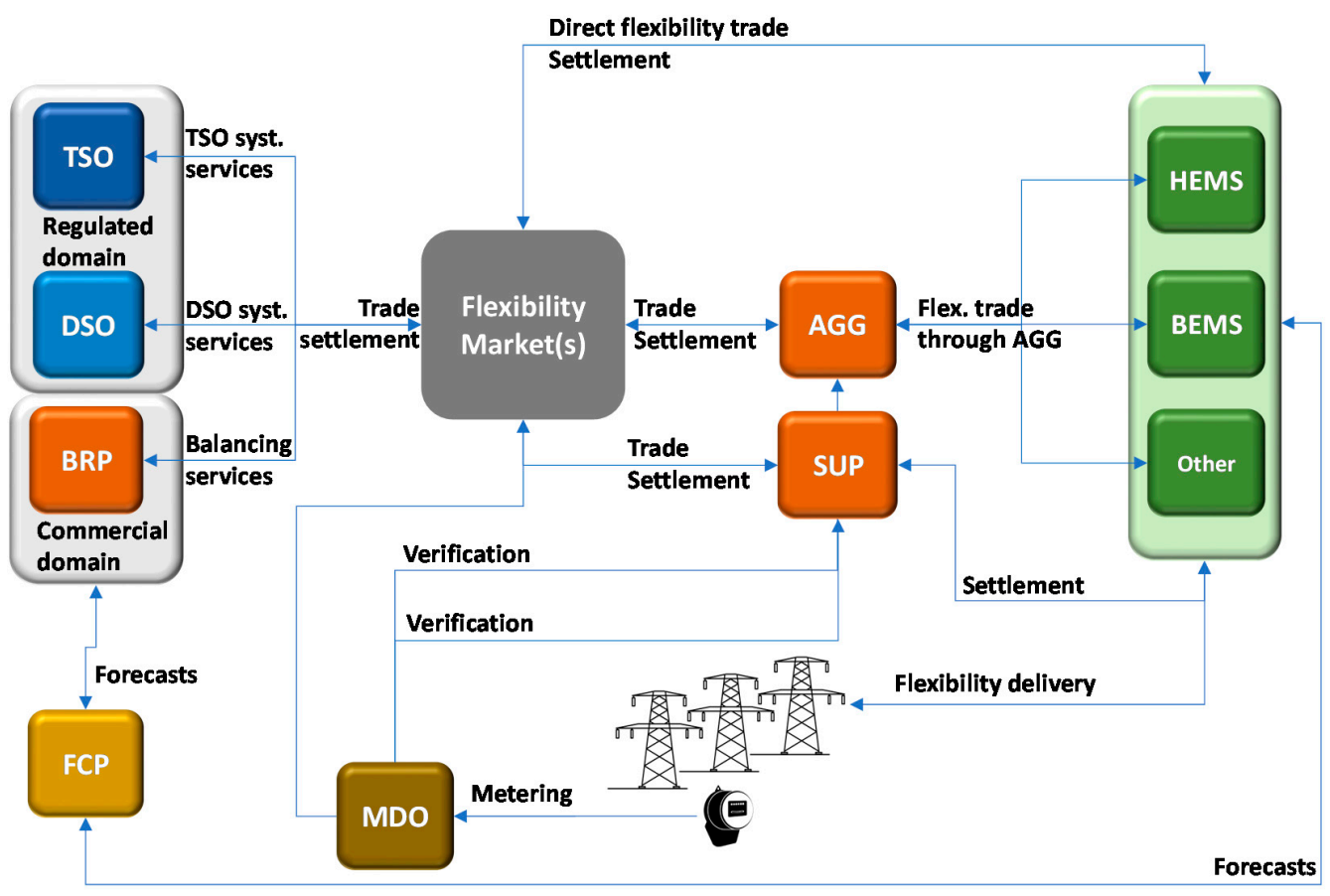

Figure 1. Schematic of the interaction between the different actors identified.

Transmission System Operator (TSO) $[20,22,23]$ is a "natural or legal person who is responsible for operating, ensuring the maintenance of and, if necessary, developing the transmission system in a given area and, where applicable, its interconnections with other systems, and for ensuring the long-term ability of the system to meet reasonable demands for the transmission of electricity" (Directive (EU) 2019/944, Article 2, see definition (35)) [19]. Its main role [23] is to transport energy from centralized producers to dispersed industrial consumers / prosumers and DSOs over its high-voltage (HV) grid. More precisely, the TSO is responsible for the reliable transmission of electricity from large-sized generation plants to regional or local electricity distribution systems [24]. The TSO must guarantee the security of supply by ensuring that the grid always remains stable [18], which entails meeting the demand for transmission to maintain generation and consumption levels balanced to keep the system's nominal frequency between its nominal limits, which is based on non-local resources such as inertia and automatic and manually activated reserves [25]. It is also responsible for keeping voltages and power flows of its grid within their operational security limits, and the sufficient active and reactive power reserves to withstand a set of predefined contingencies [18] (Articles 18 and 33). To acquire the flexibility needed, EU guideline [18] (Article 182, Section 2.1) already considers the possibility of the TSO making use of distributed active power reserves with the appropriate coordination with DSOs (see also the SmartNet project [26] or the ASM TSO-DSO Report [27] for TSO-DSO coordination schemes, summarized in Section 5).

Distribution System Operator (DSO) [2,28] is a "natural or legal person who is responsible for operating, ensuring the maintenance of, and, if necessary, developing the distribution system in a given area, and where applicable, its interconnections with other systems, and for ensuring the long-term ability of the system to meet reasonable demands for the distribution of electricity" [19] (Directive (EU) 2019/944, Article 2, see definition (29)). More precisely, the DSO is responsible for the operation (and sometimes owner) of the electricity distribution network, in some cases from HV grids through primary substations (HV/MV) to the final consumers and for ensuring the agreed power flow between distribution and transmission grids operating at LV, medium-voltage (MV) and, in some cases, HV distribution 
networks [29]. The increasing integration of RESs and other DERs, such as distributed energy storage and Electric Vehicles (EVs), has changed the distribution network paradigm, with higher uncertainty and bidirectional power flows, imposing new challenges to ensure an efficient and secure grid operation [30] and the injection of the distribution generation surplus from the DG to the TSO grid. DSOs technical challenges are mostly local, such as branch congestions, under- and over-voltages and network service restoration after local outages by reconfiguring the network or, in the cases of longer interruptions, through emergency generation groups. The local nature of distribution network problems requires finding feasible solutions within an enclosed geographical area. To do so, DSOs need to foster, as market facilitators, the participation of all types of potential market actors in a non-discriminatory and transparent way [31] to unlock the flexibility available in their distribution grid for planning and operational purposes. Market-based flexibility acquisition should be seen as preferential whenever it proves to be the most cost-efficient solution -versus other solutions, such as mandatory flexibility provision or grid reinforcements) [19].

Balance Responsible Party (BRP) [32] is a market player or its chosen representative responsible for actively balancing supply and demand for its portfolio (of producers, suppliers, AGGs, prosumers, etc.).

Metering Data Operator (MDO) [20] (also metering responsible party or metering data company) is and entity responsible for acquiring, storing and distributing validated measured data. In this case, this is rather a role than an actor, very often performed by TSOs for those assets connected to the transmission grid, or by DSOs for those connected to the distribution grid.

Aggregator (AGG) (also flexibility provider, FP, or flexibility service provider) is a third-party company that specializes on electricity demand-side participation by establishing, in practice, aggregator contracts with individual demand sites (i.e., industrial, commercial or residential consumers) to aggregate their flexibility and operate it as a single FP to TSOs, DSOs and BRPs [33] to maximize the value of that flexibility. Sometimes AGG refers only to the role of aggregating and managing a portfolio of resources, while FP refers to the role of interacting with the market to provide the flexibility managed by the AGGs. AGGs can interact with the resources they aggregate through local monitoring and control systems that can either control specific flexibility resources or through homes or building integrated energy management systems (HEMS and BEMS, respectively) [34].

Supplier (SUP) (also retailer) is the entity responsible for buying electricity in the wholesale market and selling and invoicing it to its customers. SUPs can also play the roles of BRP or AGG. When the SUP is not the AGG of its own customers, then different interaction models between them can be considered to account for the impact of the flexibility provision on the SUPs forecast [23].

Forecast Provider (FCP) (also data service provider) is an entity that provides forecasts of RES, generation and consumption based on different data (e.g., weather data and historical load flow) to be used for grid analysis and flexibility availability computations, as well as other data analytics services.

Figure 1 describes the main interactions among these actors around a generic flexibility market. AGGs (or FPs) use HEMS and BEMS to determine and aggregate the available flexibility to be offered to commercial or regulated flexibility markets. Typically, TSOs and DSOs go to the regulated markets to procure the flexibility they need (see Section 5 on TSO-DSO markets coordination), while BRPs go to commercial ones for balancing and portfolio optimization purposes. The effective provision of flexibility is then verified by the TSOs or the DSOs, depending on the procurer, based on comparing the FP commitments with the metering data collected by the metering data operator. Finally, forecast providers can provide, among other data, forecasts to help AGGs assess their available flexibility or TSOs and DSOs to assess their upcoming flexibility needs. 


\section{Characterization of TSO Needs and Services}

This chapter proposes a general characterization of TSO needs and the services required to meet current and future needs, a topic that has been extensively discussed in literature. However, even if the starting point of this work is an extensive literature review of recent institutional reports and European projects, its added value relies on the final result, which is not the collection of each individual source vision but a unified, consistent and more comprehensive approach of all the sources analyzed.

\subsection{System Needs, Scarcities, Services and Products Definitions}

As proposed in [13], a flexibility need can be defined as the requirement of a high-level strategical action or set of actions for the better operation and/or planning of the grid to enhance the security and quality of supply. This is coherent with the more specific proposal of [35], where system needs refer to ensure that the system is operated within a number of defined limits and that likely events can be properly managed. Specific needs depend on the type of grid (transmission vs. distribution) and are discussed in the next sections of this paper.

A grid service is a specific strategy designed to satisfy one or several system needs, with a set of technical requirements designed according to these needs that must be defined and complied by the service providers. For example, automatic and manual frequency restoration reserve (aFRR and $\mathrm{mFRR}$, respectively) are different services for the frequency control need (see Table 1).

In a services market context, products are the tradable units delivered by the FPs that TSOs and DSOs can procure for one or several services [13]. The complexity of adapting products to services can be left to the FPs side by developing aggregation algorithms, or to the flexibility selection or clearing algorithms, if they are able to combine different products to fulfill the services technical requirements. Differentiating services from needs (and even more products, since services are very often tied to the need they address) allows to design services (and products) able to fulfill more than one need, and to reach some level of harmonization and/or standardization (one of the main objectives of [17]). For example, at the transmission level, including locational information to restoration-reserve-like products could also allow us to use them for congestions management.

A scarcity is defined in [36] as a shortage of something that the power system has traditionally had in good supply. For example, inertia is a commonly cited scarcity in highly renewable systems due to the decrease of conventional synchronous generators. System needs may require new services approaches due to forecasted scarcities that may invalidate the way services were previously provided. For example, guaranteeing rotor angle stability of remaining synchronous generators may require new services to guarantee the required inertia in the system.

\subsection{TSO System Needs and Services}

The transition from power systems characterized by large synchronous generating units towards systems with an increasing number of smaller, variable, non-dispatchable and non-synchronous renewable generation units involves significant challenges for their safe and reliable operation. As remarked in [12], these challenges are related with new scarcities associated with the lack of frequency control, the lack of voltage control (VC), rotor angle instability problems, network congestion and the degradation of the system adequacy and restoration capability. 
Table 1. TSO needs and current and future flexibility services.

\begin{tabular}{|c|c|c|c|c|}
\hline Need & Comments & Detection Event/Trigger & Services & Service Objective \\
\hline Frequency Control & $\begin{array}{l}\text { Non-synchronous, intermittent RES } \\
\text { is replacing synchronous generators. } \\
\text { Reduced amounts of synchronous } \\
\text { generation providing inertia and/or } \\
\text { reserve capability leads to larger } \\
\text { and faster frequency oscillations } \\
\text { from its nominal value, making it } \\
\text { less controllable. }\end{array}$ & $\begin{array}{ll}\text { - } & \text { Fault; } \\
\text { - } & \text { Imbalance forecasted need; } \\
\text { Imbalance forecast errors. }\end{array}$ & $\begin{array}{ll}\text { - } & \text { Inertial response (immediate); } \\
\text { - } & \text { Fast frequency response-FFR } \\
& (<2 \mathrm{~s}) ; \\
\text { - } & \text { Frequency Containment } \\
& \text { Reserve-FCR ( } 5 \text { s to } 30 \mathrm{~s}) ; \\
\text { - } & \text { Automatic Frequency Restoration } \\
& \text { Reserve-aFRR (30 s to } 15 \text { min); } \\
\text { - } & \text { Manual Frequency Restoration } \\
& \text { Reserve-mFRR (30 s to } 15 \mathrm{~min}) ; \\
\text { - } & \text { Replacement Reserve-RR } \\
\text { (15 mins to hours); } & \text { Ramping (5 to } 10 \text { min). }\end{array}$ & $\begin{array}{l}\text { - Inertial response: minimize Rate of } \\
\text { Change of Frequency (RoCoF); } \\
\text { Fast frequency response: decelerate time } \\
\text { to reach Nadir/Zenith; } \\
\text { - FCR: contain the system frequency after } \\
\text { the occurrence of an imbalance and limit } \\
\text { its oscillations; } \\
\text { aFRR, mFRR: return frequency to } \\
\text { nominal value; } \\
\text { RR: replace reserves used to provide } \\
\text { faster products; restore/support the } \\
\text { required level of FRR to be prepared for } \\
\text { potential further system imbalances. } \\
\text { Ramping: oppose unforeseen sustained } \\
\text { divergences, such as unforecasted wind } \\
\text { or solar production changes. }\end{array}$ \\
\hline
\end{tabular}

Less synchronous generation

available leads to:

- $\quad$ Reduced capacity to provide reactive power support for steady state and dynamic VC;

Voltage Contro

- $\quad$ Reduced short circuit power (limited capacity of converter for injecting short-circuit current);

- Load and generation forecasted need;

- Forecast errors;

- Fault.
- Steady-State VC (intraday (ID), day-ahead (DA), long-term);

- Dynamic Reactive Power (<40 ms).
- $\quad$ Steady-State VC: keep voltage within limits during normal system operation;

- Dynamic Reactive Power: keep voltages within limits and restore their values to the normal range after grid disturbances. Mitigate rotor angle instability.

furthermore, the connection of RES

in the distribution system leads to

voltage variation effects. 
Table 1. Cont.

\begin{tabular}{|c|c|c|c|c|}
\hline Need & Comments & Detection Event/Trigger & Services & Service Objective \\
\hline Rotor Angle Stability & $\begin{array}{l}\text { Systems' inertia and stability are } \\
\text { heavily affected by the displacement } \\
\text { of synchronous generation. A series } \\
\text { of problems related to small signal } \\
\text { stability and transient stability } \\
\text { arise, namely: } \\
\text { - Stability margins deteriorate } \\
\text { due to the reduction in } \\
\text { synchronizing torque; } \\
\text { Transient stability margins are } \\
\text { reduced due to the } \\
\text { displacement of conventional } \\
\text { plants; } \\
\text { New power oscillation modes } \\
\text { are introduced; } \\
\text { Reduction of existing power } \\
\text { oscillations' damping. }\end{array}$ & $\begin{array}{l}\text { - } \quad \text { Fault; } \\
\text { - } \quad \text { Imbalance forecasted need; } \\
\text { - } \quad \text { Gorecast errors; } \\
\text { Grid switching. }\end{array}$ & 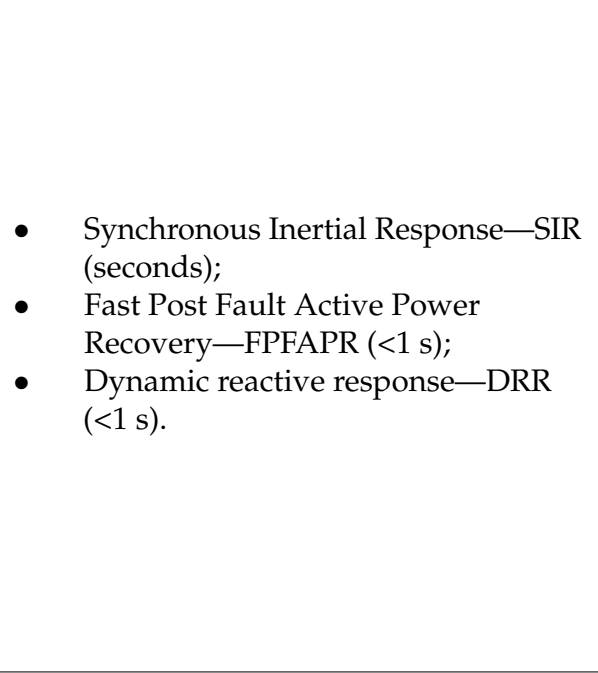 & $\begin{array}{l}\text { - SIR: minimize RoCoF; if it can be } \\
\text { provided at low MW outputs, the } \\
\text { system will be able to accommodate } \\
\text { a higher level of non-synchronous } \\
\text { generation; } \\
\text { FPFAPR: mitigate the impact of voltage } \\
\text { disturbances (including transmission } \\
\text { faults) on system frequency by } \\
\text { rewarding generators that can quickly } \\
\text { recover their MW output; } \\
\text { DRR: mitigate the weakening of the } \\
\text { system's synchronous torque, and, } \\
\text { therefore, its stability, by incentivizing a } \\
\text { reactive power throughput by wind } \\
\text { farms during disturbances. }\end{array}$ \\
\hline $\begin{array}{l}\text { Congestion } \\
\text { Management }\end{array}$ & $\begin{array}{l}\text { Transmission and distribution } \\
\text { connected RES can have periods of } \\
\text { increased feed-in power that may } \\
\text { cause transmission grid congestions. } \\
\text { This leads to: } \\
\text { - } \quad \text { Reduced network hosting } \\
\quad \text { capacity; } \\
\text { - RES curtailment. }\end{array}$ & $\begin{array}{ll}\text { - } & \text { Fault; } \\
\text { - } & \text { Load and generation } \\
\text { forecasted need; } \\
\text { - } \quad \text { Forecast errors. }\end{array}$ & $\begin{array}{l}\text { - } \quad \text { Corrective (real-time); } \\
\text { - } \quad \text { Predictive (ID or DA). }\end{array}$ & $\begin{array}{l}\text { Units redispatch to change the physical } \\
\text { flows in the transmission system and } \\
\text { relieve a physical congestion. }\end{array}$ \\
\hline System Restoration & $\begin{array}{l}\text { The decrease in the number of } \\
\text { start-capable plants on the grid } \\
\text { has a significant impact on current } \\
\text { restoration strategies, since they } \\
\text { mainly rely on large synchronous } \\
\text { generation. A reformulation of } \\
\text { these strategies is of the } \\
\text { utmost importance. }\end{array}$ & $\begin{array}{l}\text { - } \quad \text { Planned maintenance; } \\
\text { Cnplanned fault } \\
\text { correction works. }\end{array}$ & $\begin{array}{l}\text { - } \quad \text { Black-start capability (within } \\
\text { minutes [5]). }\end{array}$ & $\begin{array}{l}\text { Combined with grid reconfiguration and load } \\
\text { restoration strategies, it provides the ability } \\
\text { to restart the network after a blackout, } \\
\text { guaranteeing grid stability by keeping active } \\
\text { and reactive powers within limits. }\end{array}$ \\
\hline
\end{tabular}


Table 1. Cont.

\begin{tabular}{|c|c|c|c|c|}
\hline Need & Comments & Detection Event/Trigger & Services & Service Objective \\
\hline \multirow{2}{*}{ System Adequacy } & $\begin{array}{l}\text { The high penetration of RES } \\
\text { generation may also spawn } \\
\text { adequacy problems: }\end{array}$ & & \multirow{2}{*}{$\begin{array}{l}\text { Last-resort tender (few years } \\
\text { in advance); } \\
\text { - Strategic reserves (reserved few } \\
\text { years in advance); } \\
\text { - Capacity mechanisms. }\end{array}$} & \multirow{2}{*}{$\begin{array}{l}\text { Energy markets with transmission planning } \\
\text { may not be enough to guarantee system } \\
\text { adequacy. Other mechanisms are: } \\
\text { - Last-resort tender: specific tenders to } \\
\text { build new capacity; } \\
\text { - Strategic reserves: contract pre-decided } \\
\text { capacity a few years in advance, which } \\
\text { cannot participate in the market and is } \\
\text { only activated in case of } \\
\text { capacity shortfalls; } \\
\text { Capacity mechanisms (price-based, } \\
\text { volume-based or market-based): } \\
\text { payments assigned to the capacity } \\
\text { necessary to achieve a certain objective. }\end{array}$} \\
\hline & $\begin{array}{l}\text { The interdependencies of } \\
\text { technologies are key issues to assess } \\
\text { load and capacity factors [37]. }\end{array}$ & & & \\
\hline
\end{tabular}


These scarcities have traditionally been tackled by a combination of grid operation techniques (e.g., topology change), grid reinforcements and the operation of additional equipment, such as capacitor banks, static synchronous compensators (STATCOM), static var compensators (SVC) and synchronous condensers, as well as frequency regulation reserves for balancing. The appointed changes on transmission grids require additional support on their operation, which, if relying on the traditional resources, could delay conventional generators' decommissioning or require additional grid or equipment investments, with large expenses and reduction of environmental targets [9]. A window of opportunity, therefore, opens for the provision of flexibility services by DER.

Table 1 summarizes the main current and expected TSO needs and associated flexibility services adapted from the work performed at EU-Sysflex [12,36] and is complemented with IRENA's report on innovative AS [5]. It includes the fundamental TSO needs to be addressed, as well a brief summary of the new issues concerning each need, leading to new flexibility services.

TSO services are often divided into two major categories: (1) frequency AS and (2) non-frequency AS [12,38]. The former category includes those services related with the balancing of the system, while the latter generally encompasses, VC, CM or black-start capability. The name of the service can vary from source to source. For example, frequency control is often designated as frequency regulation, while VC is sometimes referred as voltage support. Regarding the timeframe of fast frequency response, some initiatives have been more stringent than indicated in Table 1. For example, by conducting an enhanced frequency response tender, the National Grid in the United Kingdom contracted eight battery storage facilities for a period of four years with the aim of providing sub-second rapid response frequency reserves [5].

While ramping is sometimes associated with tertiary regulation (currently called mFRR or replacement reserve, $R R$, see [39]), and involves scheduling generators to operate within 1 to $8 \mathrm{~h}$, in Table 1, it refers to the fast ramping capability. This is a new ancillary service to address the net load volatility caused by the increase of variable renewable energy generation, which is already being run, for example, by the California Independent System Operator (CAISO). CAISO implemented Flexible Ramp Up and Flexible Ramp Down Uncertainty Awards to procure the ramp up and ramp down capability for 15- and 5-min time intervals [40]. Since then, similar products have been introduced by the Midcontinent Independent System Operator (MISO), with 10-min intervals [41], or are being proposed by the New York Independent System Operator (NYISO) [5].

\section{Characterization of DSO Needs and Services}

DER flexibility for the provision of local system services for the distribution network is currently attracting considerable interest.

As was the case for TSO needs and services, this chapter also starts from an extensive literature review of recent institutional reports and European projects. However, in this case, DSO services are a still an underdeveloped topic, and a larger number of sources was analyzed. Indeed, in [13], 24 European initiatives and pilot projects were studied (see Table 2) in an attempt to characterize the distribution flexibility scarcities and needs, the related flexibility services, the market mechanisms for its procurement and the main tools needed to integrate this flexibility into DSOs planning and operation processes. A survey among selected DSOs was also performed in [13] to validate and complement the initial proposal. From [13], and with the involvement of several DSOs, such as E-REDES (former EDPD from Portugal), E.ON. (Germany), Energa (Poland) and E.DSO (association of 41 European Union DSOs), [14] proposes a further characterization of the main local system services that DSOs could profit from to operate their grid.

Finally, with all the collected information from both reports, and the additional references of this section, a classification, characterization and matching of needs and services is here proposed, as consistent as possible with all individual approaches, summarized from Tables 3-6, which, to our knowledge, is a relevant contribution to the state-of-art. 
Table 2. List of projects and initiatives analyzed.

\begin{tabular}{llll}
\hline Project Acronym & $\begin{array}{l}\text { Date of Completion } \\
\text { (or Expected) }\end{array}$ & Country(ies) & Refs. \\
\hline ATLAS & 2017 & UK & {$[42]$} \\
CoordiNet & 2022 & Spain & {$[43]$} \\
De-Flex-Market & 2015 & Germany & {$[44]$} \\
EcoGrid 2.0 & 2019 & Denmark & {$[45]$} \\
EMPOWER H2020 & 2018 & Norway & {$[46]$} \\
Enera & 2020 & Germany & {$[47]$} \\
FLECH-iPower & 2016 & Denmark & {$[48]$} \\
Flex-DLM & 2018 & Spain & {$[49]$} \\
FlexHub Eu-SysFlex & 2021 & Ireland & {$[50]$} \\
FLEXICIENCY & 2019 & Spain & {$[51]$} \\
FlexMart & 2016 & Belgium & {$[52]$} \\
Future Network Modelling Functions & 2017 & United Kingdom & {$[53]$} \\
GOPACS-IDCONS & Active platform & The Netherlands & {$[54]$} \\
InteGrid & 2020 & Portugal & {$[55]$} \\
Interflex & 2019 & France & {$[56]$} \\
INTERRFACE & 2022 & Luxembourg & {$[57]$} \\
IREMEL & Ongoing project & Spain & {$[58]$} \\
NODES & Active platform & Norway & {$[59]$} \\
Open Networks & 2020 & United Kingdom & {$[60]$} \\
Piclo Flex (and Piclo) & Active platform & United Kingdom & {$[61]$} \\
PlatOne & 2023 & Germany & {$[62]$} \\
Power Potential & Ongoing project & United Kingdom & {$[63]$} \\
SENSIBLE & 2018 & Germany & {$[64]$} \\
USEF & Active organization & The Netherlands & {$[65]$} \\
\hline
\end{tabular}

\subsection{Detailing the DSO Local System Needs}

As already mentioned, the distribution network operation deals mainly with local problems, so that feasible solutions must be found within an enclosed geographical area. The more common issues are congestions, voltages and service restoration actions, which are traditionally addressed through a combination of specific DSO equipment, grid reconfigurations and investments planning. Conventional CM and VC tools and DSOs assets have been designed for typical radial LV and MV networks, where power flows are unidirectional. However, the increasing RES-based generation combined with meshed distribution topologies requires a greater level of coordination. For LV networks, VC is typically limited to the manual offline regulation of power transformers, which can be particularly limited on longer power lines or when reverse power flows are established [66]. Furthermore, ensuring the $\mathrm{N}-1$ criterion might not be viable considering, for example, the difficulties in building new lines [18]. Therefore, DER flexibility can be exploited as an alternative to the installation of additional equipment or grid reinforcements to overcome the shortcomings listed above.

Table 3 summarizes the EUniversal research [13] by identifying the DSO needs more frequently addressed across 24 recent initiatives and by DSOs themselves for tackling such challenges, while Table 4 reviews in more detail these DSO needs and corresponding flexibility services.

\subsection{Flexibility Services for the DSO}

Based on [13,14], Table 4 lists all needs and services identified, and summarizes their general specification, and Table 5 describes the main attributes to characterize the technical requirements of a service, which can serve as guidelines for the definition of the products to deliver that service on a market environment. Following the template proposed at Table 5, Table 6 collects the main specifications for the services identified. 
Table 3. Number of initiatives addressing each identified DSO need.

\begin{tabular}{ll}
\hline DSO Need & $\begin{array}{l}\text { Number of Projects Covering the Need } \\
\text { (of a Total of 25) }\end{array}$ \\
\hline Congestion Management & 21 \\
Voltage Control & 14 \\
Support for Network Planning & 10 \\
Phase Balancing & 8 \\
Support for Extreme Events & 7 \\
Support for Planned/Unplanned Operations & 7 \\
\hline
\end{tabular}

Table 4. DSO needs and future flexibility services.

\begin{tabular}{|c|c|c|c|c|}
\hline Need & Comments & Detection Event/Trigger & Services & Service Objective \\
\hline $\begin{array}{l}\text { Congestion } \\
\text { Management }\end{array}$ & $\begin{array}{l}\text { Violation of the physical limitations of } \\
\text { the network (i.e., exceeding the assets } \\
\text { thermal limits) caused, for example, by } \\
\text { high power consumption during peak } \\
\text { hours, use of heat pumps or } \\
\text { simultaneous charging of EVs or DGs } \\
\text { power generation during off-peak hours. }\end{array}$ & $\begin{array}{l}\text { Fault followed by an } \\
\text { outage and service } \\
\text { restoration; } \\
\text { Forecasted } \\
\text { congestion; } \\
\text { Load and generation } \\
\text { forecast errors }\end{array}$ & $\begin{array}{ll}\text { - } & \text { Operational CM } \\
& \text { (real-time); } \\
\text { - } & \text { Short-term } \\
& \text { planning CM } \\
& \text { (ID or DA). }\end{array}$ & $\begin{array}{l}\text { Mitigate congestions to } \\
\text { guarantee consumers supply } \\
\text { and avoid grid } \\
\text { equipment failures. }\end{array}$ \\
\hline $\begin{array}{l}\text { Voltage } \\
\text { Control }\end{array}$ & $\begin{array}{l}\text { Voltage magnitude outside admissible } \\
\text { limits with different consequences } \\
\text { depending on the duration and } \\
\text { amplitude of the deviations (i.e., under- } \\
\text { and over-voltages). Can be associated or } \\
\text { not to congestion, occurring typically } \\
\text { during peak hours, concentrated } \\
\text { charging of EVs, use of heat pumps or } \\
\text { DGs power generation during off-peak } \\
\text { hours, among others. }\end{array}$ & $\begin{array}{l}\text { Load and generation } \\
\text { forecast errors }\end{array}$ & $\begin{array}{ll}-\quad & \text { Short-term } \\
\text { planning VC } \\
\text { (ID to DA); } \\
\text { Operational VC } \\
\text { (real-time) }\end{array}$ & $\begin{array}{l}\text { Keep voltages within } \\
\text { specific safe bands and } \\
\text { restore their values to the } \\
\text { normal range after grid } \\
\text { disturbances, to minimize } \\
\text { reactive power flows, } \\
\text { investments, technical } \\
\text { losses and, potentially, } \\
\text { RES curtailment. }\end{array}$ \\
\hline $\begin{array}{l}\text { Voltage/Phase } \\
\text { Unbalances }\end{array}$ & $\begin{array}{l}\text { Voltage quality problem arising from the } \\
\text { unequal distribution of load and } \\
\text { generation among the three phases of the } \\
\text { network. Affects mainly LV networks } \\
\text { and can cause excessive heating and } \\
\text { losses in three phase induction machines, } \\
\text { excessive currents in three-phase power } \\
\text { electronic devices, the reduction of } \\
\text { feeders' capacity and increased } \\
\text { harmonic distortion. }\end{array}$ & $\begin{array}{ll}\text { - } & \text { Forecasted need; } \\
\text { - } & \text { Forecast errors; } \\
& \text { Unbalanced faults in } \\
\text { MV network. }\end{array}$ & $\begin{array}{ll}\text { - } & \text { Short-term } \\
\text { planning VC } \\
\text { (ID to DA); } \\
\text { Operational VC } \\
\text { (real-time) }\end{array}$ & $\begin{array}{l}\text { Improve the balance of loads } \\
\text { and generations among the } \\
\text { three phases of the network } \\
\text { to reduce losses, increase the } \\
\text { distribution network } \\
\text { capacity, reduce the risk of } \\
\text { failures and improve } \\
\text { voltage profiles. }\end{array}$ \\
\hline Voltage Sag & $\begin{array}{l}\text { Voltage sags (or dips) typically result } \\
\text { from faults occurring in transmission or } \\
\text { HV networks and can lead to the } \\
\text { malfunction and disconnection of } \\
\text { different loads and or generators. More } \\
\text { severe disturbances can compromise the } \\
\text { system's stability and eventually cause } \\
\text { the collapse of the grid's voltage level. }\end{array}$ & - $\quad$ Voltage dips. & $\begin{array}{l}\text { Operational } \\
\text { based on local } \\
\text { VC functions } \\
\text { (real-time). }\end{array}$ & $\begin{array}{l}\text { Provide automatic reactive } \\
\text { power compensation to help } \\
\text { compensate the voltage sag } \\
\text { and avoid the disconnection } \\
\text { of loads and generation. }\end{array}$ \\
\hline $\begin{array}{l}\text { Support for } \\
\text { Planned and } \\
\text { Unplanned } \\
\text { Maintenance } \\
\text { Action }\end{array}$ & $\begin{array}{l}\text { Using flexibility as an alternative to } \\
\text { disconnecting costumers, power cutting } \\
\text { or using fuel generators when faced with } \\
\text { planned or unplanned maintenances (the } \\
\text { last case resulting from outages where it } \\
\text { is not possible to temporarily restore } \\
\text { service to all consumers). }\end{array}$ & $\begin{array}{l}\text { Planned } \\
\text { maintenances } \\
\text { followed by field } \\
\text { work to restore } \\
\text { service }\end{array}$ & $\begin{array}{ll}\text { - } & \begin{array}{l}\text { Operational CM } \\
\text { (real-time); }\end{array} \\
\text { - } & \text { Short-term } \\
\text { planning CM } \\
\text { (ID or DA); } \\
\text { - } \quad \text { Islanding; } \\
\text { - } \quad \text { Voltage and } \\
\text { frequency } \\
\text { control; } \\
\text { Black-start } \\
\text { capability) }\end{array}$ & $\begin{array}{l}\text { Reduce the System } \\
\text { Average Interruption } \\
\text { Duration Index } \\
\text { (SAIDI) and Energy } \\
\text { Not Supplied (ENS); } \\
\text { Reduce the usage of } \\
\text { fuel generators; } \\
\text { Increase the periods } \\
\text { where it is possible to } \\
\text { perform network } \\
\text { maintenance actions } \\
\text { without deteriorating } \\
\text { the quality of service }\end{array}$ \\
\hline
\end{tabular}


Table 4. Cont.

\begin{tabular}{|c|c|c|c|c|}
\hline Need & Comments & Detection Event/Trigger & Services & Service Objective \\
\hline $\begin{array}{l}\text { Support for } \\
\text { Network } \\
\text { Planning }\end{array}$ & $\begin{array}{l}\text { Using flexibility to postpone network } \\
\text { investments to solve either current or } \\
\text { forecasted physical congestions related } \\
\text { to reduced network capacity (overload or } \\
\text { voltage violation) and improve network } \\
\text { reliability in cases where building new } \\
\text { lines are not desirable (e.g., nature } \\
\text { conservation areas). }\end{array}$ & $\begin{array}{l}\text { - } \quad \text { Forecasted need; } \\
\text { - } \quad \text { Risk assessment. }\end{array}$ & $\begin{array}{l}\text { Long-term VC } \\
\text { combined with } \\
\text { long-term CM } \\
\text { (months to years } \\
\text { ahead); } \\
\text { Islanding. }\end{array}$ & $\begin{array}{l}\text { Use flexibility in } \\
\text { combination with grid } \\
\text { investments to solve } \\
\text { forecasted physical } \\
\text { congestions related to } \\
\text { reduced network capacity } \\
\text { (overload or } \\
\text { voltage violation). }\end{array}$ \\
\hline $\begin{array}{l}\text { Support for } \\
\text { Extreme } \\
\text { Events }\end{array}$ & $\begin{array}{l}\text { DSO need related to an increase in the } \\
\text { resilience of distribution networks } \\
\text { and/or capacity to quickly recover from } \\
\text { extreme events. Such events often lead to } \\
\text { equipment damage, with consequences } \\
\text { ranging from congestion and voltage } \\
\text { problems to grid islanding scenarios. }\end{array}$ & $\begin{array}{l}\text { - Failures due to } \\
\text { extreme and natural } \\
\text { disasters. }\end{array}$ & $\begin{array}{ll}\text { - } & \text { Islanding; } \\
\text { - } & \text { Black-start } \\
& \text { capability; } \\
\text { - } & \text { Emergency load } \\
& \text { control; } \\
\text { - } & \text { Interruptible load; } \\
\text { - } & \text { DER; } \\
\text { - } & \text { Backup } \\
& \text { generation } \\
\text { capacity. }\end{array}$ & $\begin{array}{l}\text { Increase grid resiliency } \\
\text { for minimizing the } \\
\text { impact of extreme } \\
\text { weather events; } \\
\text { Islanding: improve } \\
\text { continuity of supply in } \\
\text { case of unavailability } \\
\text { of the main grid; } \\
\text { Black-start: provide } \\
\text { the ability to restore } \\
\text { service locally after } \\
\text { a blackout; } \\
\text { Emergency load } \\
\text { control: provide load } \\
\text { reductions that lessens } \\
\text { stress on the grid; } \\
\text { Backup generation } \\
\text { capacity: make } \\
\text { sustainable power } \\
\text { available for islanded } \\
\text { operations. }\end{array}$ \\
\hline
\end{tabular}

Table 5. Attributes for the characterization of a grid service.

\begin{tabular}{|c|c|}
\hline Parameter & Description \\
\hline & Moment when the service is contracted. \\
\hline Procurement timeframe & $\begin{array}{l}\text { (a) Operational (real-time); } \\
\text { (b) Short-term planning (D-1 to M-1); } \\
\text { (c) Long-term planning ( }>\text { M-1 to Y-1, or more). }\end{array}$ \\
\hline Reservation and/or activation & If procurement requires reservation in advance (e.g., D-1) or activation in real-time or both. \\
\hline Mode of activation & $\begin{array}{l}\text { Activation of flexibility can either be manual, at the request of the operator or automatic, in case of } \\
\text { local control strategies. }\end{array}$ \\
\hline Expected duration of the response & $\begin{array}{l}\text { Estimation of the time required to solve the technical problem, which is necessary to evaluate the } \\
\text { capability of the DER to provide a requested service. }\end{array}$ \\
\hline Full activation time & $\begin{array}{l}\text { Period comprehended between activation and full delivery of the service; encompasses seconds, } \\
\text { minutes or hours depending on the resource. }\end{array}$ \\
\hline Geographic scope & $\begin{array}{l}\text { Identifies if the response must be provided by node or for a wider scope; from local (LV) to regional } \\
\text { (MV) and cross-regional (HV), can also be defined per point of common coupling (PCC), feeder or } \\
\text { substation; relevant for understanding if and how resources can be aggregated. }\end{array}$ \\
\hline Mandatory status & $\begin{array}{l}\text { Participation of the mobilized flexibility can be mandatory (in which case, non-delivery is met by } \\
\text { penalties) or procured on the market (in which case, DER can be remunerated according } \\
\text { to participation). }\end{array}$ \\
\hline Aggregation & $\begin{array}{l}\text { If the service allows the aggregation of resources as a way of meeting minimum quantities at a } \\
\text { specific location. }\end{array}$ \\
\hline Minimum quantity & Minimum power that can be provided per offer; usually in the order of magnitude from kW to MW. \\
\hline Maximum quantity & Maximum power that can be provided per offer; usually in the order of magnitude from $\mathrm{kW}$ to $\mathrm{MW}$. \\
\hline Deactivation period & $\begin{array}{l}\text { Represents the estimated time for a resource to stop delivering a service upon receiving a } \\
\text { deactivation signal; usually in the order of magnitude from seconds to minutes. }\end{array}$ \\
\hline Minimum duration of delivery period & $\begin{array}{l}\text { Minimum duration of the service provision (coincides with the step for product definition, when } \\
\text { services are defined in steps of equal time length); a typical value encountered is } 15 \text { min. }\end{array}$ \\
\hline Maximum duration of delivery period & Maximum duration of the service provision; usually in hours. \\
\hline
\end{tabular}


Table 6. Basic specifications of each identified service [14].

\begin{tabular}{|c|c|c|c|c|c|c|c|c|}
\hline & \multicolumn{2}{|c|}{ Services Addressing CM } & \multicolumn{2}{|c|}{ Services for VC and PB } & \multirow{2}{*}{$\begin{array}{l}\text { Services Providing } \\
\text { Support for } \\
\text { Network Planning }\end{array}$} & \multicolumn{3}{|c|}{$\begin{array}{l}\text { Services For Support For Planned/Unplanned Operation } \\
\text { (Including Extreme Events) }\end{array}$} \\
\hline & Operational CM & Short-Term Planning CM & Operational VC & Short-Term Planning VC & & Mobile Generation Capacity & Black-Start & Islanding \\
\hline Procurement timeframe & Real-time & Daily or ID & Close to real-time & Daily, ID or DA & $1-3$ years & Short-term, considering plann & or forecasted e & \\
\hline $\begin{array}{l}\text { Reservation and/or } \\
\text { activation }\end{array}$ & Activation & Both are possible ${ }^{1}$ & $\begin{array}{l}\text { Activated when } \\
\text { needed }^{2}\end{array}$ & Both are possible ${ }^{1}$ & Reservation & Reservation $^{3}$ & & \\
\hline Mode of activation & \multicolumn{2}{|l|}{ Manual } & \multicolumn{2}{|c|}{ Manual $^{4}$ or automatic ${ }^{5}$} & Manual & Manual & & Manual and automatic ${ }^{6}$ \\
\hline $\begin{array}{l}\text { Expected duration of } \\
\text { the response }\end{array}$ & \multicolumn{2}{|c|}{$\begin{array}{l}\text { Restricted by thermal limits and activation time of } \\
\text { the resource }\end{array}$} & \multicolumn{2}{|c|}{$\begin{array}{l}\text { MV: from minutes up to } 1 \mathrm{~h} ; \\
\mathrm{LV} \text { : from } 15 \text { min up to } 3 \mathrm{~h}^{7}\end{array}$} & NA & Variable $^{8}$ & & No more than $1-3 \mathrm{~h}$ \\
\hline Geographic scope & \multicolumn{2}{|c|}{ Local $^{9}$, regional or cross-regional } & \multicolumn{2}{|l|}{ Local $^{10}$} & Local $^{11}$ & Local $^{10}$ & Local $^{12}$ & Local $^{13}$ \\
\hline Mandatory status & Mandatory & $\begin{array}{l}\text { Mandatory or procured } \\
\text { on market }\end{array}$ & Mandatory & $\begin{array}{l}\text { Non-mandatory } \\
\text { (procured on market or } \\
\text { provided through } \\
\text { redispatch) }\end{array}$ & $\begin{array}{l}\text { Mandatory or not, } \\
\text { depending on the risk }\end{array}$ & Non-mandatory & & \\
\hline Aggregation & $\begin{array}{l}\text { Subject to restrictions } \\
\text { since this is a } \\
\text { fast-response service }\end{array}$ & $\begin{array}{l}\text { May be limited by market } \\
\text { and technical } \\
\text { requirements }\end{array}$ & $\begin{array}{l}\text { Considered when } \\
\text { limited to a PCC }{ }^{14}\end{array}$ & $\begin{array}{l}\text { Considered, even at } \\
\text { voltage levels different } \\
\text { than the one for which the } \\
\text { problem occurs }{ }^{15}\end{array}$ & $\begin{array}{l}\text { Considered for } \\
\text { resources of equal } \\
\text { and/or lower } \\
\text { voltage levels }\end{array}$ & NA & & \\
\hline Maximum quantity & \multicolumn{5}{|c|}{ Limited by the installed capacity } & & & \\
\hline Deactivation period & $\begin{array}{l}\text { Dependent on the } \\
\text { power ramping of } \\
\text { the resource }\end{array}$ & $15 \mathrm{~min}$ & $\begin{array}{l}\text { Dependent on the } \\
\text { power ramping of } \\
\text { the resource }\end{array}$ & $15 \mathrm{~min}$ & NA & $\begin{array}{l}\text { Dependent on the power } \\
\text { ramping of the resource }\end{array}$ & \multicolumn{2}{|c|}{$\begin{array}{l}\text { Less than } 1 \text { min after the reconnection to the } \\
\text { main grid }\end{array}$} \\
\hline $\begin{array}{l}\text { Minimum duration of } \\
\text { delivery period }\end{array}$ & $15 \mathrm{~min}$ & & & & Several hours & $30 \mathrm{~min}$ & $>30 \mathrm{~min}$ & $15 \mathrm{~min}$ \\
\hline $\begin{array}{l}\text { Maximum duration of } \\
\text { delivery period }\end{array}$ & \multicolumn{4}{|l|}{ No limit } & & & \multicolumn{2}{|c|}{$\begin{array}{l}\text { Limited by the installed energy capacity of } \\
\text { the provider }\end{array}$} \\
\hline
\end{tabular}

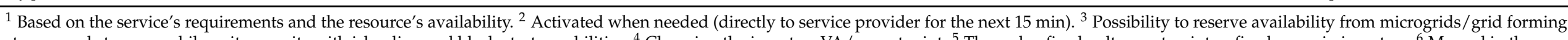

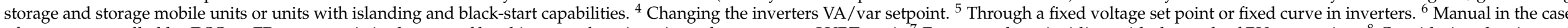

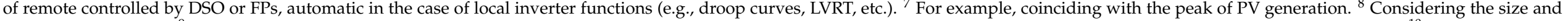

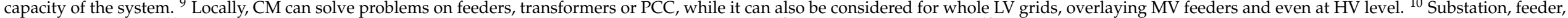

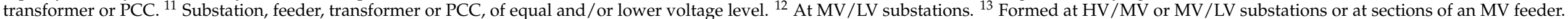

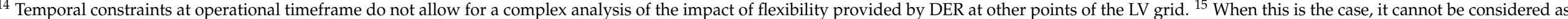
the simple capacity summation of the aggregated resources. 


\subsubsection{Services Addressing Congestions Management}

$\mathrm{CM}$ represents the need to mitigate/avoid physical congestions, a condition defined by Commission Regulation (EU) 2015/1222 [67] as "any network situation where forecasted or realised power flows violate the thermal limits of the elements of the grid and voltage stability or the angle stability limits of the power system".

In practice, such limitations can be caused by high power consumption during peak hours, use of heat pumps, simultaneous charging of EVs or excessive power generation from DGs, among others.

The ubiquitous response for current-related issues relies on active power management, regardless of the geographic scope, time frame or event/trigger. A direct correlation can, however, be established between the events/triggers that originate the need for CM and the time frame where they take place. Faults such as short-circuits can cause congestion in the feeders that remain connected, or during the restoration of service, requiring an automatic and fast response, whereas the operational forecasting of (possible) congestions usually takes place on an intraday to day(s)-ahead timescale. Going even further, congestions can also be forecasted during network planning and maintenance scheduling, which are planned months to years ahead [4], where CM could help to defer and/or avoid grid reinforcements [2].

Services for $\mathrm{CM}$ are then viewed by DSOs as both planning and operation tools. Indeed, CEER's report [2] states that "DSO congestion management can take place long before, prior to, during or after existing wholesale market clearing and as far as just before the (gate) closure of the balancing market". In addition, the increasing penetration of DER and the gradual uptake of the markets driven by the system needs will likely increase the availability of flexibility for CM purposes, and support short-term liquidity and a higher procurement for services closer to real-time [12]. Although [12] only addresses AS for TSO, this will be also applicable to DSO thanks to mechanisms such as the aggregation of small-scale DERs.

Three CM services are derived in this paper, differing mainly on the procurement timeframe, namely: Operational CM, Short-Term Planning CM and Long-term CM.

Operational CM (sometimes called corrective CM as in [14]) is associated to congestion problems detected in real-time, which are often linked to forecast errors or equipment failures and requires (near) real-time control action of flexible resources.

Implementing a market-based operational $\mathrm{CM}$ service would be viable if the reserve capacity is negotiated before the related problems arise, or if the fault correction can be delayed until the flexibility is acquired. Otherwise, operational CM must rely on mandatory regulated mechanisms to allow very fast activations of the available flexibility. However, considering the uncertainty associated to network contingencies, the computation of the necessary reserve capacity would require the adoption of network planning tools capable of dealing with uncertainty and risk. Additionally, adequate products need to be defined for these timeframe (e.g., considering only activation price with activation limits defined).

Short-Term Planning CM goes from day-ahead (DA) or intraday (ID) to month-ahead (the later mainly for maintenance planned purposes), and is based on the analysis of demand and generation forecast scenarios that may anticipate congestion problems. In this case, all terms (DA, ID and month-ahead), basically share the same tools and strategies. For these timeframes, the DSO can address the CM need with a combination of flexibility acquisition and grid reconfigurations.

Long-term planning was considered in this paper as a specific service and is discussed in Section 4.2.4.

\subsubsection{Services for Voltage Control}

VC aims at keeping voltages within acceptable voltage limits, according to Standard EN50160 [68]. Adequate voltage regulation in distribution network is critical to restore voltages values to their normal range after grid disturbances given its strong influence on 
grid performance and on several types of loads, particularly on electronic loads, inverterbased DER and induction machines.

As presented in Table 4, and following Standard EN50160 [68], three voltage quality problems were identified that could potentially be solved with flexibility resources, namely: under and overvoltage problems, voltage unbalances and voltage sags.

Voltage regulation in distribution networks has been mainly performed through the control of OLTC at the HV/LV substations, with the objective of compensating the voltage along the radial feeders. However, this control principle can become ineffective in MV and LV networks integrating high shares of RES, where reverse power flows can occur, causing the voltage to increase in the end of the feeders [66]. This problem is accentuated in $\mathrm{LV}$ networks, due to the low reactance-over-resistance $(\mathrm{X} / \mathrm{R})$ ratio of the cables. $\mathrm{LV}$ networks are also three-phase four wire networks where the loads and DER are mostly single-phase and unevenly connected to the three phases, consequently causing voltage unbalance problems that cannot be solve at the HV/MV substation.

Increasing voltage regulation and balancing capabilities in MV and LV networks through DER control has been foreseen in several countries that have DER grid connection requirements [69]. This implies either the remote control of DER by the DSO or local DER inverter functions, usually referred to as dynamic VC. However, these local control functions do not allow the DSO to forecast the network behavior in predictive management, and in scenarios of high integration of RES, this can lead to unwanted oscillatory voltage behavior [70]. In this sense, coordinated VC has been proposed in the literature in addition to these local control strategies [71].

Voltage sags are considered power quality disturbances, defined in EN 50160 [68] as a "sudden reduction of the supply voltage to a value between $90 \%$ and $1 \%$ of the declared voltage $U_{c}$ (reference voltage) followed by a voltage recovery after a short period of time (...) between $10 \mathrm{~ms}$ and $1 \mathrm{~min}^{\prime \prime}$. These can occur in both MV and LV networks, as previously described, originating from faults occurring at the transmission level. Larger disturbances can be further caused by the disconnection of large shares of DER generation. DER connected at MV and LV should, therefore, be endowed with Low Voltage Ride Through (LVRT) capabilities, which may help mitigate the effects of these larger disturbances [69,72].

VC is considered for the LV and MV networks and can be tackled by active and reactive power management (AP-M and RP-M). Solutions for all timeframes are considered interesting, depending, as for CM, on the event/trigger of the need for VC. With the exception of voltage sags that can result from faults requiring real-time response to compensate the voltage dip, voltage magnitude and unbalance compensation are triggered mainly by the forecasted status of the MV and LV network for the next day or hours and consequent errors detected in (near) real-time. Therefore, as for CM, VC services can be classified by their timeframe into Operational VC and Short-Term Planning VC.

Operational VC consists of the capability of regulating voltage in (near) real-time, either through remote control of DER active and/or reactive power or dynamic VC schemes. It is particularly directed for localized problems, requiring a quick response of the available flexibilities.

Short-Term Planning VC is designed for forecasted disturbances, again from DA or ID to month-ahead timeframes. For example, a forecastable problem that occurs cyclically and repeats at specific times (such as PV production in summer on a high insolation location) would be best tackled by the frequent acquisition of a service that extends over long periods of time.

The planning horizon and the voltage level of the network are key factors in the definition of VC services. Both of them, although sharing general technical assumptions across different timeframes, can be substantially different depending on the voltage level. First, the geographical scope of the services will generally be limited, since VC needs are localized in nature. Nonetheless, VC problems may also span across several voltage levels. Both the amount of power and the duration of the service can, for example, vary significantly when considering LV lines (which are more resistive, and therefore, more 
suited for AP-M) or MV/HV lines (which are more inductive, and therefore, more suited for RP-M).

In addition to voltage regulation, reactive power management in the distribution network also has the objective of meeting the limitation of reactive power import/export with the transmission network, following ENTSO-E recommendations [68]. Reactive power regulation will even become more urgent in high RES integration scenarios, where a large share will be connected to the distribution network.

\subsubsection{Services for Phase Balancing}

As described previously, voltage unbalances are considered a voltage quality problem leading to an inadequate operation of loads and increased losses. In the MV network, voltage unbalance typically results from unbalanced faults causing unbalanced voltage in the MV/LV substation. The problem is more common in LV networks, due to the uneven connection of single-phase loads and generation between the three-phases of the network. This problem is expected to take increased proportions in the future due to the widespread of EV charging, microgeneration and the increasing adoption of self-consumption profiles by prosumers.

DSOs traditionally tackle this problem by reconfiguring the LV network and redistributing LV consumers/prosumers between phases. However, this can represent a significant amount of field work that may imply service interruptions. In this sense, the control of single-phase DER is an opportunity to increase the capability of managing the power flow in each phase. Both single-phase and three-phase DER can help compensate voltage unbalance through AP-M or RP-M strategies, implemented either by remote active and/or reactive control or locally (in the case of three-phase DER), adopting specific voltage unbalance compensation strategies.

The three types of VC are adequate to help solve voltage unbalance problems, which should be tackled together with VC. In fact, maintaining voltages within acceptable limits will also help to minimize voltage unbalance problems.

\subsubsection{Support for Network Planning}

Network planning aims at identifying the most efficient solution (or set of solutions, depending on the adopted planning criteria), regarding the expansion or the reinforcement of an existing distribution grid. Before the advent of DER, the conventional planning paradigm aimed primarily at accommodating the foreseen increase in electricity consumption within a certain time horizon, e.g., 10 years. This was achieved by identifying the investments (new lines, new transformers, new substations, etc.) that were required to meet the electricity demand, as well as their associated cost.

In recent years, however, planning the network's expansion has become an increasingly difficult endeavor to DSOs, as the growing integration of DER, especially volatile renewable generation, is causing the network's equivalent net load (generation minus the load) to become ever more unpredictable. At the same time, environmental restrictions are limiting the number of possibilities for placing new lines and substations, as new legislation tends to penalize investments that involve building infrastructures outside the already existing distribution network. In this setting, flexibility can be particularly beneficial to the network, as it can contribute to alleviate or even eliminate some of the issues that lead to the reinforcement needs. For example, the availability of storage devices in the network can help to absorb the excess of renewable generation at critical times, reducing the number of overvoltages and branch congestions throughout the planning horizon. Similarly, controllable loads can be transferred from peak hours to other periods of the day, which can limit the occurrence of undervoltages throughout the planning horizon.

Flexibility should, then, be explicitly included during the network planning as an alternative to grid investments to determine the most cost-effective solutions, especially to solve occasional constraints. Network planning usually considers congestions and voltages issues together, not being addressed independently, so no differentiation between CM and 
VC long-term planning is usually needed. The timeframe is usually 1 to 3 years, enough to allow for grid investments. For this service, flexibility should be previously reserved, but only activated if the predicted grid constraints are still expected based on the most recent grid analysis, close to real-time. This flexibility could be mandatory when large potential risks and consequences are expected in the grid operation.

\subsubsection{Services to Support Planned/Unplanned Operation (Including Extreme Events)}

Flexibility can be used as a mean to avoid the disconnection of costumers (for example through operational CM and VC) or, when an outage occurs, following planned or unplanned events, can help minimize the energy not supplied (ENS) and the time of interruption, either by supporting network reconfiguration or by enabling islanded operation, minimizing the use of fuel generators. This would also help increasing networks' resilience against natural disasters and extreme weather, increasing the mechanism to prevent, mitigate and recover the system [73]. Services addressing this need would ultimately prevent supply interruption in parts of the grid, reduce the duration and frequency of outages and reinforce the resilience of areas where power supply is critical.

Planned and unplanned operations can then be supported by CM and VC described previously, supporting for example network reconfiguration actions required both in planned and unplanned actions. When no network reconfiguration alternatives are available, services such as islanding, black-start, emergency load control and mobile generation capacity will help improving the network reliability and resilience against extreme weather events.

The islanding service consists of providing power supply to all or part of the clients that are affected by a service interruption, through the establishment of a small microgrid (or island) endowed with the adequate control functionalities to operate it. However, islanding has technical complexities and costs that could be larger than the N-1 (or even reinforced) grid planning criterion. These technical challenges include [14,74]:

- Frequency and voltage regulation capability, provided by one or more grid forming units capable of establishing the grid voltage in magnitude and phase of the islanded grid (microgrid) and providing fast frequency and voltage regulation.

- Synthetic inertia, provided also by the grid forming unit(s) or by other DER with specific inertia emulation functionalities, exploiting the controllability of DER and their power electronic power inverters [74].

- Frequency support, so that DER can locally change the power outputs as a function of the microgrid frequency to maintain the local power balance (e.g., active power/frequency drop characteristics).

- Voltage support, so that DER can change the power outputs as a function of the microgrid voltage (e.g., active or reactive power/voltage drop characteristics).

- The existence of sufficient production and flexibility (which could also come from the demand side) to keep the instantaneous energy balance of the microgrid by also providing load and generation reserve capacities. Load imbalances can, for example, be met by fast responsive storage devices operating in flawless coordination with local generation and flexible loads.

Based on the above points, the islanding service can be viewed as consisting of a set of complimentary services, some of them overlapping with other CM and VC services already discussed, to be provided by DER. Further considerations need to be established when considering islanded areas where multiple DSOs are operating, and where assets within the island are either providing flexibility services to TSOs or pre-contracted market services. The islanding service becomes more relevant for locations where compliance with the $\mathrm{N}-1$ criterium is challenging due to the impossibility of constructing new lines or interconnections.

Black-start is a service for addressing partial or total blackouts in sections of the main grid, as a consequence of extreme events for example, and is complementary to the above islanding services to reestablish power in a local microgrid affected by a previous outage. 
The resources to provide such a service are not very different from the ones considered for islanding, and include local generation and storage units, either stationary or mobile. DER should also have black-start capability, and fast frequency and voltage services to operate in islanded mode [75]. To ensure the stability and balance of the recently restored system, adequate communication channels between DSOs and all parties involved is also fundamental.

Emergency load control may be needed for additional load shedding when other solutions (market based) cannot provide the required amount to maintain stability and prevent further problems, while avoiding generation curtailment. A social merit order should guide the selection of the loads to be curtailed, so that, for example, hospitals, police stations and firefighter's headquarters are usually the last in that merit order. Regulatory mandates are preferred to market mechanisms by DSOs (the latter of which should have already been depleted before), since it is an emergency service, with manual activation to ensure that priority loads are not interrupted.

Finally, islanding and black-start services could be provided by mobile generation capacity, which, similarly to diesel emergency generation, provide an alternative and temporary power to supply to consumers connected to a certain grid area or to avoid under-voltages and stability problems caused by planned or unplanned operation or extreme events. This service can be market-based and could rely on long-term bilateral agreements between DSOs and FPs.

\subsection{Challenges for Upscaling the Integration of Flexibility in Distribution Networks: DSO Vision Insights}

Taking advantage of the flexibility of DER for improving distribution network efficiency, reliability and resilience is widely recognized by DSOs. However, three main barriers have been identified for promoting market-based flexibility mechanisms at the distribution level, namely: regulatory, network observability and deployment of DER control and management systems [13].

Although Directive 2019/944 for electricity markets incentivize DSOs to procure flexibility services, current national regulatory frameworks are distinct in the different countries. Indeed, as reported in [8], national regulations often restrict the offering of certain services or the participation of some FPs, as in the UK, where policy and regulatory barriers are hindering the participation of smart solutions such as DR. However, in other cases (see also [8]), these services cannot be financed, or the technology has not yet been fully researched and assessed to provide these services, as is the case in Greece, where the digitalization of the national networks is still in the preliminary rollout phase, namely the installation of digital, smart metering devices. Oftentimes, the case is that no specific regulation has yet been adopted for the use of flexibility in the distribution network.

Regarding the list of needs, the survey conducted by EDSO in [13] identified VC as the more relevant need, followed by $\mathrm{CM}$. This was an interesting result, considering $\mathrm{CM}$ was the most addressed service in the projects analyzed (see Table 3). This can be explained by the concerns towards the growing integration of DER and EV in LV networks, causing mainly voltage magnitude and unbalanced phase problems associated to the specific characteristics of these networks (e.g., radial topology and three-phase four wire network with single-phase DER and loads connected) in a network with reduced monitoring and control capabilities.

For VC and CM, both RP-M and AP-M are already addressed by most DSOs, particularly considering mandatory schemes. Implementing market-based flexibility services implies a change in distribution network monitoring and control strategies towards a more predictive approach. A predictive network management strategy will enable the forecast of technical restrictions (e.g., voltage and congestions problems) and to define the optimal operation strategy considering both network assets and flexibility resources [76].

Currently, the main Advanced Distribution Management Systems (ADMS) are moving towards this predictive management strategy, particularly for HV and MV networks, incorporating load and generation forecast tools and adapting traditional power system 
simulation tools, such as optimal power flow [64]. The main challenge remains to develop an adequate network management framework for the LV networks, considering the low observability due to reduced monitoring capabilities and the high error of LV load forecasts. Specific tools need to be developed, taking advantage of smart metering infrastructure and its historical data and capable of dealing with poor topology mapping and network feeder electrical parameter characterization $[55,64,76]$.

Similarly, current network planning methodologies follow a business-as-usual model considering conventional network reinforcement investments. To plan and assess the benefit of long-term flexibility products, flexibility must be integrated as an additional asset for planning purposes [64,77].

Therefore, implementing CM and VC through market-based mechanisms for shortterm and long-term planning requires significant updates in DSO systems and might represent a costly solution to implement in the next 5 years for some DSOs [13]. The potential value of services for support planned and unplanned actions are still considered residual by DSOs, particularly islanding and black-start services. Islanding operation in most countries is not allowed, also requiring wider implementation of network's automatic switching equipment and complex network protection systems with adaptive capabilities [78]. However, growing integration of RES and network resilience concerns are increasing the interest on the possibility of islanding operation and distributed service restoration, where tackling resilience becomes a more relevant operation and planning criterion $[79,80]$.

The early-stage development of local flexibility markets can also be explained by the reduced number of FPs. The deployment of self-consumption solutions, EVs and other flexible loads supported by interoperable energy management solutions will help scale up flexibility in distribution networks, increasing the liquidity of local flexibility markets [15].

In conclusion, upscaling market-based flexibility services in distribution networks requires: (1) the development of adequate national regulation framework; (2) increasing the distribution networks observability and moving towards the predictive network management framework, including adequate tools for LV networks; (3) promoting the deployment of interoperable energy management solutions for increasing the remote-control capabilities of flexible resources.

\section{Basic TSO-DSO Coordination Mechanisms}

The revision work in [13], on the projects and initiatives that led to the characterization of DSO needs and services, was also the basis for the identification of the main market mechanisms used to acquire these services. To do so, based on existing literature on TSO-DSO markets organization, but complemented with the experience gained from this analysis, the main TSO-DSO market mechanisms are revisited and described from a functional point of view, and the main options selected to acquire the services are also identified in Table 7. A critical discussion of these results is also provided based on the market organizations complexities, data sharing and level of development of such markets, as well as a comparison with similar initiatives in the USA and Australia.

The use of distributed flexibility from both TSO and DSO is a challenging problem that requires improving the existing coordination mechanisms among them. When flexibility services are market-based, it is common to simplify TSO-DSO coordination mechanisms into several schemes that help to characterize and understand their main features and differences. Building from existing literature (see for example $[13,27,81,82]$ or more recently [83]), we suggest (based on the work carried out under the Interconnect Project [21]) a further simplification of the main market-based coordination mechanisms by focusing on the three more common approaches.

\section{- $\quad$ TSO centralized flexibility market (M1)}

This approach is closer to the current situation (see Figure 2, model M1), where the flexibility is only procured by the TSO in its own centralized market(s), where aggregated DER are also allowed to participate under certain conditions. 
A pre-qualification process of the DER can take place to guarantee that their activation does not compromise the DSO's grid, possibly followed by a close to real-time DSO validation before the flexibility activation, to guarantee the distribution grid's safe operation.

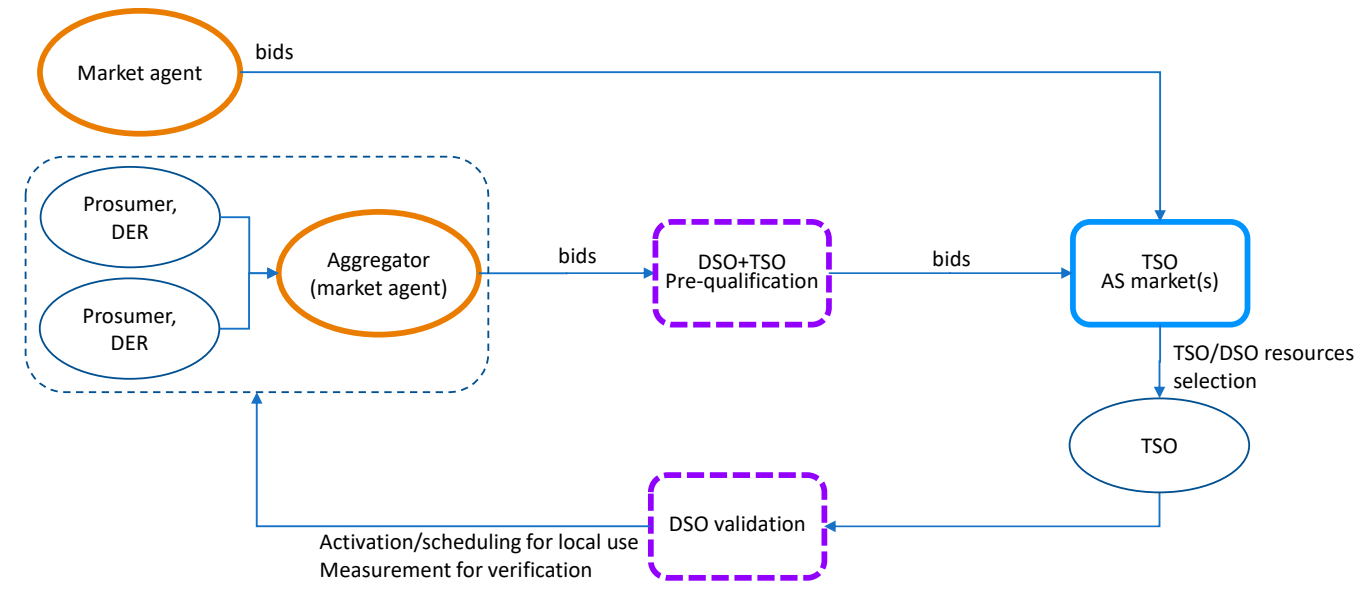

Figure 2. Centralized TSO flexibility market (M1).

- Local (DSO) and global (TSO) flexibility markets

$\bigcirc \quad$ In this approach, the flexibility offered by the DER is managed in a local DSO flexibility market, while TSO has its own flexibility market(s).

- The DSO uses the local resources for its own flexibility needs, and the remaining flexibility is made available to the TSO, with two possible sharing mechanisms:

(a) The TSO has direct access to the DER bids (Figure 3, model M2), so that it can directly select those bids that solve its needs in the most efficient way. With this approach, the DSO may want to validate the bids selected by the TSO before their activation to guarantee its own grid safe operation.

(b) As an alternative, the TSO can agree with the DSO (Figure 4, model M3) on the desired flexibility at the TSO-DSO connection points, and the DSO manages its local market for its own purposes, but also to satisfy, where possible, the TSO needs according to the agreed flexibility profile.

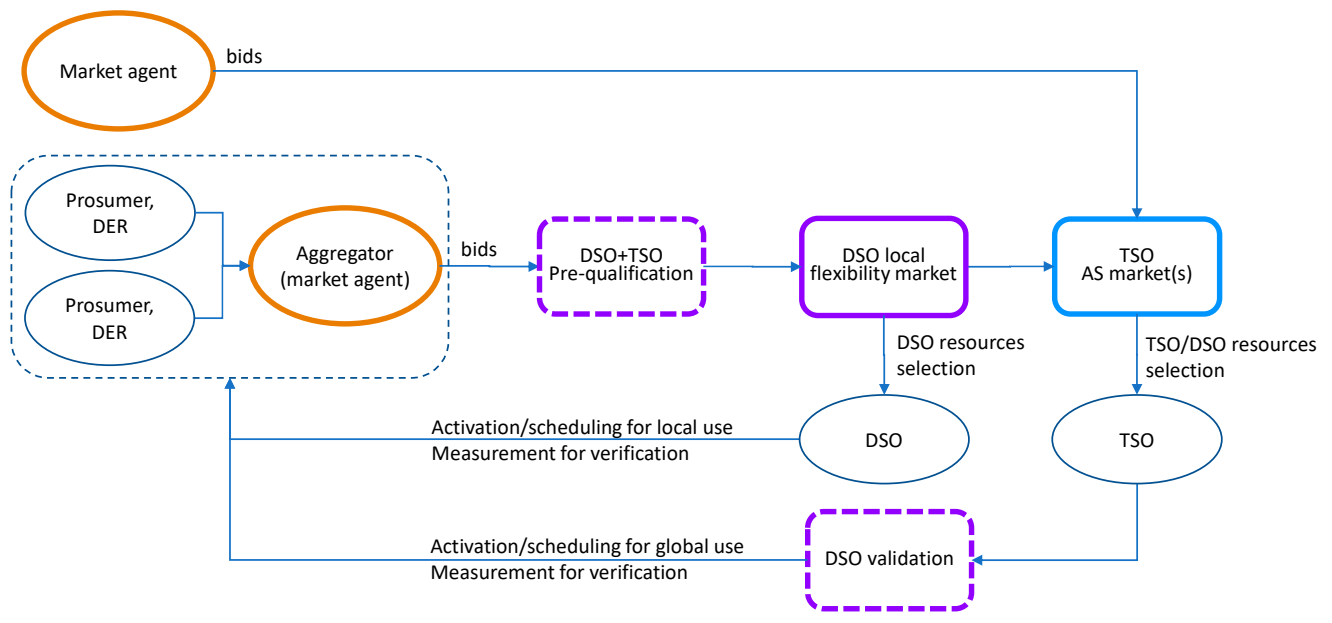

Figure 3. Local (DSO) and global (TSO) flexibility markets with resources sharing (M2). 


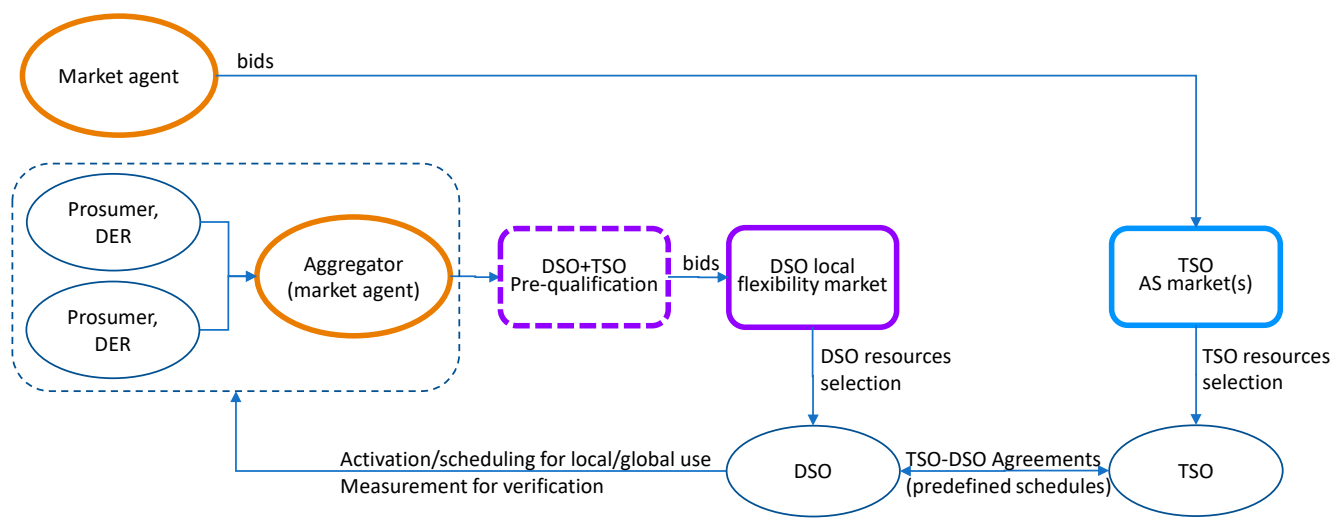

Figure 4. Local (DSO) and global (TSO) flexibility markets with shared responsibility (M3).

Coordination may sometimes include the communication from the DSO to the TSO of the flexibility activated locally to avoid potential TSO imbalances. However, in many cases, locally activated flexibilities have a very low significant impact on TSO balancing.

\section{- Common TSO-DSO flexibility market}

This approach is based on a unique flexibility market, where all the FPs can send their bids to be selected by TSO and DSO (Figure 5, model M4).

- The selection of these bids by DSO and TSO is carried out in a coordinated process, with many possible levels of complexity, and should take into account the constraints of all the grids involved.

- If the resources are used to resolve grid constraints, the TSO or DSO need their locational information.

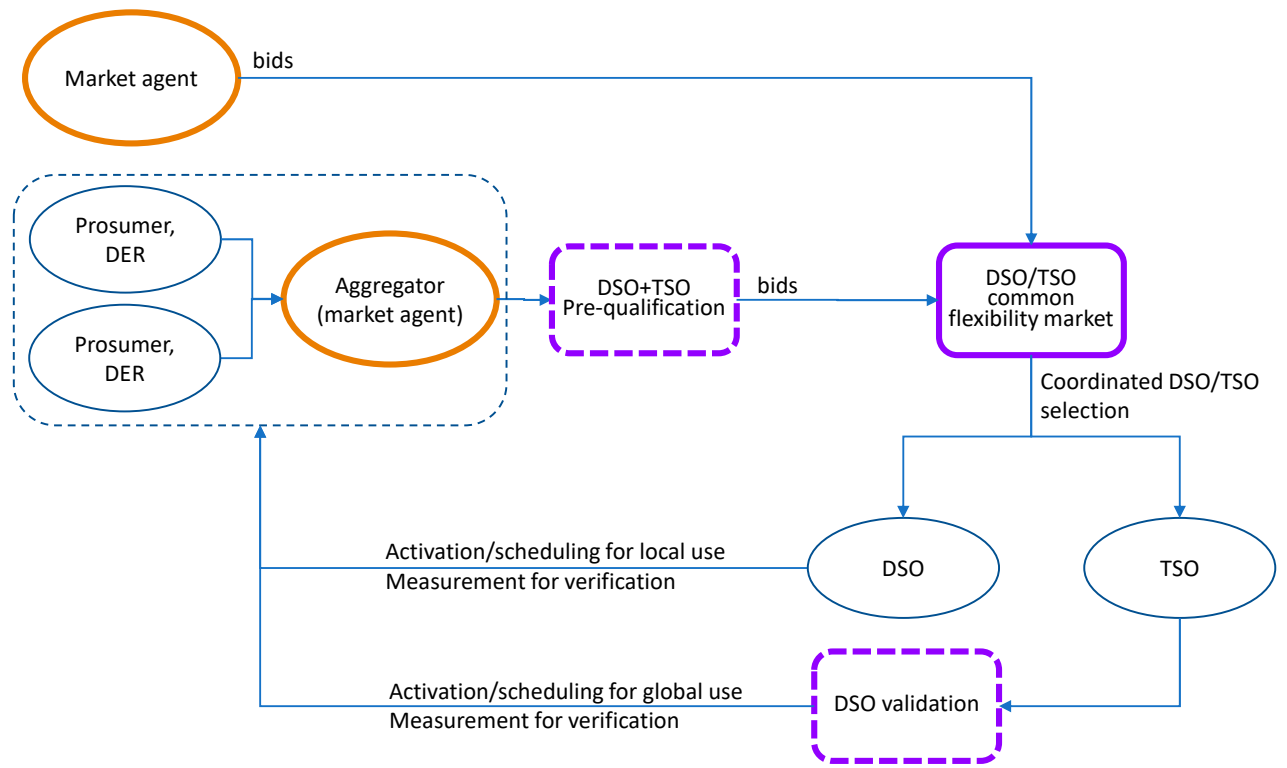

Figure 5. Common TSO-DSO flexibility market (M4).

In [13,81], an additional TSO-DSO-BRP coordination model is identified, where, in the same flexibility market, commercial and regulated flexibility trades take place (model M5 in [13]). However, Table 7, which identifies the TSO-DSO coordination mechanisms of the projects and initiatives analyzed in [13], shows that this mechanism is not very often selected. Indeed, system operators prefer to acquire flexibility in regulated markets to avoid competing with commercial parties that could lower their priority access and compromise their systems operation. In addition, the discussion on flexibility priority access is also a hot topic among DSOs and TSOs, with DSOs generally preferring models 
M2 and M3, which give them priority to their local flexibility, and TSOs opting for model

M4, which give them better visibility and access to the distributed flexibility resources.

Table 7. Main coordination mechanisms addressed in the initiatives analyzed.

\begin{tabular}{lll}
\hline TSO-DSO Coordination Mechanism & $\begin{array}{l}\text { Correspondence to EUniversal } \\
\text { Market Organization [13] }\end{array}$ & Addressed in \\
\hline Centralized TSO flexibility market & M1 & $\begin{array}{l}\text { CoordiNet, FlexHub Eu-Sysflex, SmartNet, } \\
\text { TDX-ASSIST }\end{array}$ \\
\hline $\begin{array}{l}\text { Local (DSO) and global (TSO) flexibility } \\
\text { markets with resources sharing }\end{array}$ & M2 & $\begin{array}{l}\text { CoordiNet, De-Flex-Market, EcoGrid 2.0, } \\
\text { EMPOWER H2020, FLECH-iPower, Flex-DLM, } \\
\text { FlexHub Eu-Sysflex. FLEXICIENCY, FlexMart, } \\
\text { GOPACS-IDCONS, InteGrid, Interflex, IREMEL, } \\
\text { NODES, Piclo Flex (and Piclo), SENSIBLE, } \\
\text { SmartNet, USEF }\end{array}$ \\
\hline $\begin{array}{l}\text { Local (DSO) and global (TSO) flexibility } \\
\text { markets with shared responsibility }\end{array}$ & M3 & CoordiNet, FlexHub Eu-Sysflex, SmartNet \\
\hline \begin{tabular}{l} 
Common TSO-DSO flexibility market \\
\hline
\end{tabular} & M4 & Coordinet, INTERRFACE, SmartNet \\
\hline
\end{tabular}

The review performed in [13] indicates that the TSO-DSO coordination with local (DSO) and global (TSO) flexibility markets (models M2 and M3) were the most frequently addressed among the project and initiatives listed in Table 2, as Table 7 shows. This is a logical consequence of the fact that these markets organizations are apparently simpler, with a lower optimization complexity, also allowing DSOs, the main facilitators of the use of distributed flexibility, a better control and use of the resources located at their grids. In addition, grid data are not shared between grid operators, something that can cause privacy and security concerns. However, also note that this conclusion could sometimes be misleading, since most initiatives, given their nature (commercial such as Piclo Flex, Enera or GOPACS-IDCONS; conceptual such as FLECH-iPower or SENSIBLE; research papers such as De-Flex-Market or EcoGrid 2.0) do not provide an extensive discussion on coordination mechanisms and befell on the category of market mechanism associated with that coordination scheme (market mechanisms M2 or M3). In fact, richer discussions were found on projects that addressed different types of coordination mechanisms, namely CoordiNet, FlexHub Eu-Sysflex, USEF and INTERRFACE. For example, INTERRFACE focuses its discussion on the hypothesis of having or not separate or overlapping merit order lists for $\mathrm{CM}$ and for the provision of balancing services. In any case, even if the efficiency of common markets (mainly model M4) is widely recognized, data sharing issues and co-optimization and coordination complexity are also widely acknowledge as potential barriers, and since DSO flexibility markets are still a matter of research, smaller progressive steps can support starting by simpler approaches, such as M2 and M3 models, which seems to be coherent with what was observed in Table 7.

Note that the project SmartNet was not included on the list of projects reviewed by EUniversal, since it can be considered the basic reference for the identification and characterization of the main TSO-DSO coordination mechanisms and, as such, addresses them all, being the base for all the following works. Reference [26] summarizes its main findings: centralized schemes show higher technical and economic performance but are very much dependent on generation and consumption forecasts' quality and have larger computational complexity; small-sized local markets can suffer from a high risk of illiquidity; and information and communication technology (ICT) investments play a fundamental role for any coordination scheme. Regarding this last topic, project TDX-Assist [84] focused on developing ICT tools that are scalable, secure and interoperable for data exchange between TSO and DSO, and can be taken as a fundamental reference on the ICT involved in TSO-DSO coordination procedures. However, it does not analyze whether different ICT requirements are needed, depending on the different market mechanisms described in this 
section. The use cases related to the data exchange required for market operations, such as acquiring balancing services at the distribution network by the TSO, were performed under a centralized market scheme [85], basically corresponding to model M1. Other use cases involving, for example, a congestion at the border between distribution and transmission grids, are not considered to be solved by acquiring flexibility under any particular market mechanism. Also related to communication interfaces, [86] proposes a conceptual architecture based on three different interfaces. The first one is a direct TSO-DSO interface to guarantee security, stability and resilience, with fast data exchanges for emergency situations, and for medium- and long-term coordination for TSO-DSO grid connections by exchanging structural information, forecasts, needs and resources activation. The second one is a shared resources interface, where the distributed resources shared by TSO and DSO can easily interact with both operators by providing structural information, baselines and measurements. The third one includes the market interfaces, for the flexibility providers to offer their services and TSO and DSO to buy them. These market interfaces would be dependent on the specific market organizations selected, and should take care of avoiding double bids selection, harmful activations for other SO grids, etc.

When looking at other projects outside the EU context, the Australian project Open Energy Networks [87] is very interesting, since it also classifies TSO-DSO coordination mechanisms (or the equivalent entities there) into the Single Integrated Platform Model (SIP), Two-Step Tiered Platform Model (TSTP), Independent Distribution System Operator Model (IDSO) and Hybrid Model. A closer look at this proposal shows strong similarities with what is proposed here, although in these markets, as in the USA, and unlike in the EU, energy, reserves and congestions are solved at once in the market optimization. Taking this into account, the SIP model, where a single platform is managed by AEMO, the Australian system and market operator, where aggregators can offer DER flexibilities, can be considered similar to model M1. In the TSTP model, the DSO (called distribution network service provider or DNSP) is responsible for managing and optimizing its network and the resources located at its network, as in the M2 and M3 models, giving the priority for using DER resources to the DSO before the TSO (or IDSO in this case) can use them. The IDSO model is based on the TSTP, but an independent market operator manages the local flexibility market, so they still can be matched to functional models M2 and M3. Finally, the Hybrid model is based on a single platform that includes transmission, distribution and DER constraints, which are optimized together, as in the M4 model. Once again, the larger efficiency of this common optimization is highlighted.

Another Australian pilot project, completed in 2019, the Networks Renewed [88-90], conducted by Australian Renewable Energy Agency (ARENA), Essential Energy (EE) and United Energy (UE), also experimented with using aggregated distributed resources, in grid services' provision, to solve local LV voltage problems. In the assumed market model, the DSO entity is responsible for managing the DER flexibility, using it for local voltage services (reactive power management), and after that, the remaining flexibility is made available for the global AS market (if needed by the TSO entity). Again, through the clearance of the local market prior to the system-wide market, it can be assumed that this model is close to M2 or M3 market models.

Focusing on the USA, current TSOs (or equivalent entities such as the independent system operator or ISO) seem to focus on integrating DER for the provision of balancing services. This is, for example, the case of the PJM Synchronized Reserve market [91,92], the NYISO Wholesale market [93,94], the MISO's Load Modifying Resource market [95] and the AESO Load Shed Services for Imports [96], all in the USA and based on market model M1. In 2011, the U.S. National Renewable Energy Laboratory proposed an Energy Imbalance Market (EIM) for balancing and congestion management in several areas of the Western Interconnection [97]. Two different possibilities were considered: (1) a centralized inter-area balancing market in which DER can participate (model M1); and (2) local and global flexibility markets for congestion management, in which the DSO secures its own flexibility needs, while also allowing the DER, within its control area, to offer flexibility to 
other areas (other TSO or DSO), provided that the bids are cleared by a security-constrained economic dispatch (model M3). As of January 2021, a total of 11 TSOs and DSOs integrated the EIM [98], with four other members being expected to join by the end of the year.

\section{Conclusions}

This paper presents a practical review of the existing and potential new ASs for TSOs and new local system services for DSOs, with an emphasis on DSO services that will help to address the new operation paradigm of the distribution grids. It also summarizes the main TSO-DSO coordination mechanisms and flexibility markets organizations proposed in the literature to acquire this flexibility. The work in EUniversal project, including the analysis of 24 research projects and initiatives dealing with DSO flexibility markets, is the base for the identification of DSO services, the assessment of their relative relevance for the DSO operation, and the identification of the main TSO-DSO coordination mechanisms for flexibility acquisition.

Enabling the participation of most potential players in the system services, with a special focus on DER, is essential to provide flexibility for the system operation at all levels: at the transmission level to account for new flexibility resources in a scenario where thermal power plants, traditional FPs, are being progressively decommissioned, and, at the distribution level, to cope with the increasing complexity of the distribution grids operation, both to keep the security and quality of supply in a cost-effective way and to transport the DG surplus from the decentralized generation to the transmission grid. The analysis of this evolving transformation allows to identify new needs, scarcities and responsibility in the operation of the transmission and distribution grids, as the basis to identify and assess future grid services for a better and cost-effective grid operation, especially in the DSO domain, where the precise definition and deployment of these new grid services is still starting.

On the TSO side, grid services are very well established, and it is the move from centralized to DG, with the decrease of dispatchable resources, that raises the existence of new scarcities, and the need of compensating them with new flexibility resources from the distribution side. The lower controllability of the new resources leads to the challenge of guaranteeing the firmness and adequacy of the system. The shifting to renewable generation and a more volatile net demand may require new fast reserves and ramping services, new flexibility resources, and the decrease of physical inertia due to the decommissioning of synchronous generators may require new inertia markets and the participation of virtual inertia providers.

On the DSO side, grid services are still being discussed, but there seems to be a clear consensus on the fact that VC and CM will need to be addressed first. The development of these grid services to profit from the existing distributed flexibility also requires a careful assessment of the most cost-effective solutions compared to more conventional practices, such as the traditional approach of fit-and-forget approach based on grid reinforcements. Indeed, the complexity and costs of developing potential new services is sometimes a concern that needs to be properly assessed, and which will certainly depend on each grid's characteristics and expected evolution for the coming years. Technological advancements also have an important role in increasing the controllability of DER and unlocking their potential flexibility. The increasing role of the distribution systems in supporting extreme events and outages, to increase the overall system resiliency, also provides new responsibilities to DSOs. Although services such as islanding or black-start capabilities are not yet seen as essential, they are expected to gain relevance in the coming years.

TSO-DSO coordination mechanisms are also under constant debate, and both the complexity and the interests of TSOs and DSOs may sometimes make this coordination difficult. Indeed, the most efficient approaches are those where all flexibility resources are shared and optimally selected considering some kind of social welfare that simultaneously takes into account TSO and DSO grid constraints and needs. However, this may require grid data sharing and the establishment of complex selection criteria and 
priorities that may not properly satisfy all parties. In addition, moving from the current system, where no distributed flexibility has largely been used yet, to this unique TSO-DSO market framework may involve computational and organizational complexities that may be better addressed with previous intermediate steps. This may explain why separated but coordinated TSO and DSO flexibility markets are apparently preferred, as they could be a reasonable approach to first unlock the distributed flexibility and develop the new DSO market-based system services, as a previous step towards a more integrated and efficient TSO-DSO coordination.

Author Contributions: Conceptualization, R.S., E.A., R.F., J.V. and C.G.; methodology, R.S., E.A., R.F., J.V. and C.G.; formal analysis, R.S., E.A., R.F., J.V. and C.G.; investigation, R.S., E.A., R.F., J.V. and C.G.; resources, R.S., E.A., R.F., J.V. and C.G.; data curation, R.S., E.A., R.F., J.V. and C.G.; writing—original draft preparation, R.S., E.A., R.F., J.V. and C.G.; writing-review and editing, R.S., E.A., R.F., J.V. and C.G.; supervision, J.V. and C.G.; project administration, C.G.; funding acquisition, C.G. All authors have read and agreed to the published version of the manuscript.

Funding: The research leading to these results has received funding from the European Union's Horizon 2020-The EU Framework Programme for Research and Innovation 2014-2020, under grant agreement No. 864334, EUniversal project. The sole responsibility for the content lies with the authors. It does not necessarily reflect the opinion of the Innovation and Networks Executive Agency (INEA) or the European Commission (EC). INEA or the EC are not responsible for any use that may be made of the information it contains.

Institutional Review Board Statement: Not applicable.

Informed Consent Statement: Not applicable.

Data Availability Statement: No new data were created or analyzed in this study. Data sharing is not applicable to this article.

Acknowledgments: The authors would like to express their gratitude to the EUniversal DSO partners (E-REDES former EDPD from Portugal, E.ON. from Germany and Energa from Poland) and to E.DSO (European Distribution System Operators association), as well as to other EU-SysFlex and Interconnect partners that have, to some extent, help us to elaborate this integral vision on TSO and DSO system services.

Conflicts of Interest: The authors declare no conflict of interest.

\section{References}

1. IRENA. Innovation Landscape Brief: Future Role of Distribution System Operators; International Renewable Energy Agency: Abu Dhabi, United Arab Emirates, 2019.

2. CEER (Council of European Energy Regulators-Distribution Systems Working Group). CEER Paper on DSO Procedures of Procurement of Flexibility, Ref: C19-DS-55-05; Distribution Systems Working Group: Brussels, Belgium, 2020.

3. EURELECTRIC. EURELECTRIC's Vision about the Role of Distribution System Operators (DSOs)—A EURELECTRIC Paper; EURELECTRIC: Brussels, Belgium, 2016.

4. E.DSO for Smart Grids. Flexibility: The Role of DSOs in Tomorrow's Electricity Market; E.DSO: Brussels, Belgium, 2014.

5. IRENA. Innovation Landscape Brief: Innovative Ancillary Services; International Renewable Energy Agency: Abu Dhabi, United Arab Emirates, 2019.

6. EUniversal Consortium. D5.1 EUniversal: Identification of Relevant Market Mechanisms for the Procurement of Flexibility Needs and Grid Services. 2021. Available online: https://euniversal.eu/wp-content/uploads/2021/02/EUniversal_D5.1.pdf (accessed on 20 July 2021).

7. IRENA. Market Integration of Distributed Energy Resources; International Renewable Energy Agency: Abu Dhabi, United Arab Emirates, 2019.

8. Forouli, A.; Bakirtzis, E.A.; Papazoglou, G.; Oureilidis, K.; Gkountis, V.; Candido, L.; Ferrer, E.D.; Biskas, P. Assessment of Demand Side Flexibility in European Electricity Markets: A Country Level Review. Energies 2021, 14, 2324. [CrossRef]

9. Pirbazari, A.M. Ancillary Services Definitions, Markets and Practices in the World. In Proceedings of the 2010 IEEE/PES Transmission and Distribution Conference and Exposition: Latin America (T D-LA), Sao Paulo, Brazil, 8-10 November 2010; pp. 32-36.

10. Demoulias, C.S.; Malamaki, K.-N.D.; Gkavanoudis, S.; Mauricio, J.M.; Kryonidis, G.C.; Oureilidis, K.O.; Kontis, E.O.; Martinez Ramos, J.L. Ancillary Services Offered by Distributed Renewable Energy Sources at the Distribution Grid Level: An Attempt at Proper Definition and Quantification. Appl. Sci. 2020, 10, 7106. [CrossRef] 
11. Oureilidis, K.; Malamaki, K.-N.; Gallos, K.; Tsitsimelis, A.; Dikaiakos, C.; Gkavanoudis, S.; Cvetkovic, M.; Mauricio, J.M.; Maza Ortega, J.M.; Ramos, J.L.M.; et al. Ancillary Services Market Design in Distribution Networks: Review and Identification of Barriers. Energies 2020, 13, 917. [CrossRef]

12. EU-SysFlex Consortium. EU-SysFlex: Product Definition for Innovative System Service (D3.1). 2019. Available online: https: / / eu-sysflex.com/wp-content/uploads/2019/08/D3.1_Final_Submitted.pdf (accessed on 20 July 2021).

13. EUniversal Consortium. D1.2 EUniversal-Observatory of Research and Demonstration Initiatives on Future Electricity Grids and Markets. 2021. Available online: https:/ / euniversal.eu/wp-content/uploads/2021/02/EUniversal_D1.2.pdf (accessed on 20 July 2021).

14. EUniversal Consortium. D2.1 EUniversal-Grid Flexibility Services Definition. 2021. Available online: https://euniversal.eu/wp -content/uploads/2021/02/EUniversal__D2.1.pdf (accessed on 20 July 2021).

15. Interconnect Consortium. Resources-Interconnect Project. Available online: https://interconnectproject.eu/resources/ (accessed on 23 March 2021).

16. INTERRFACE Consortium. Public Deliverables I INTERRFACE. Available online: http://www.interrface.eu/public-deliverables (accessed on 17 April 2021).

17. OneNet Consortium. Public Deliverables. Available online: https://onenet-project.eu/public-deliverables/ (accessed on 17 April 2021).

18. European Union Commission Regulation (EU) 2017/1485 of 2 August 2017 Establishing a Guideline on Electricity Transmission System Operation 2017. Available online: https://eur-lex.europa.eu/legal-content/EN/TXT/?uri=CELEX\%3A32017R1485 (accessed on 20 July 2021).

19. European Union. Directive (EU) 2019/944 of the Parliament and the Council of 5 June 2019 on Common Rules for the Internal Market of Electricity and Amending Directive 2012/27/EU, 2019. Available online: https:/ / eur-lex.europa.eu/legal-content/EN /TXT/?uri=CELEX\%3A32019L0944 (accessed on 20 July 2021).

20. ENTSO-E. The Harmonised Electricity Market Role Model, 2020. Available online: https:/ / eepublicdownloads.entsoe.eu/cleandocuments/EDI/Library/HRM/Harmonised_Role_Model_2020-01.pdf (accessed on 20 July 2021).

21. Interconnect Project. Available online: https:/ / interconnectproject.eu/ (accessed on 20 July 2021).

22. Glowacki Law Firm. European Union Emissions Trading Scheme: Transmission System Operators (TSOs). Available online: https: / / www.emissions-euets.com/internal-electricity-market-glossary / 622-transmission-system-operators-tsosRecom mended\%20practices\%20for\%20DR\%20market\%20design\%20(usef.energy) (accessed on 26 May 2021).

23. De Heer, H.; van der Laan, M. USEF: Workstream on Aggregator Implementation Models. Recommended Practices and Key Considerations for a Regulatory Framework and Market Design on Explicit Demand Response, 2017. Available online: https: //www.usef.energy/app/uploads/2016/12/Recommended-practices-for-DR-market-design.pdf (accessed on 20 July 2021).

24. Renewables Grid Initiative. Factsheet Transmission System Operators, 2015. Available online: https://renewables-grid.eu/filea dmin/user_upload/Files_RGI/RGI_Publications/Factsheets/RGI_Factsheet_basic.pdf (accessed on 20 July 2021).

25. ENTSO-E. Synchronous Area Framework Agreement for Regional Group Continental Europe-Annex 1: Policy on LoadFrequency Control and Reserves, 2019. Available online: https:/ / eepublicdownloads.entsoe.eu/clean-documents/Publications /SOC/safa/1_-_Policy_on_Load-Frequency_Control_and_Reserves.pdf (accessed on 20 July 2021).

26. SmartNet Consortium. SmartNet: TSO-DSO Coordination for Acquiring Ancillary Services from Distribution Grids-The SmartNet Project Final Results, 2019. Available online: http://smartnet-project.eu/wp-content/uploads/2019/05/SmartNet-Bo oktlet.pdf (accessed on 20 July 2021).

27. Brazier, R.; Cunha, L.; Hermans, P.; de Jong, G.; Knop, T.; Lallemand, M.; Merkel, M.; Risnes, A.; Rodríguez, M.; de Wit, P. TSO-DSO Report: An Integrated Approach to Active System Management; CEDEC, E.DSO, ENTSO-E, Eurelectric; GEODE: Brussels, Belgium, 2019.

28. Glowacki Law Firm. European Union Emissions Trading Scheme: Distribution System Operators. Available online: https://ww w.emissions-euets.com/internal-electricity-market-glossary/623-distribution-system-operators-dsos (accessed on 26 May 2021).

29. E.DSO (last). Why SmartGrids: What Is a DSO? Available online: https:/ / www.edsoforsmartgrids.eu/home/why-smart-grids/ (accessed on 26 May 2021).

30. Lopes, J.P.; Madureira, A.G.; Matos, M.; Bessa, R.J.; Monteiro, V.; Afonso, J.L.; Santos, S.F.; Catalão, J.P.S.; Antunes, C.H.; Magalhães, P. The future of power systems: Challenges, trends, and upcoming paradigms. Wiley Interdiscip. Rev. Energy Environ. 2020, 9, e368. [CrossRef]

31. European Union Commision Regulation (EU) 2019/943 of the European Parliament and of the Council of 5 June 2019 on the Internal Market for Electricity, 2019. Available online: https:/ / eur-lex.europa.eu/legal-content/EN/TXT/?uri=CELEX\%3A3201 9R0943 (accessed on 20 July 2021).

32. European Union Emissions Trading Scheme-Legal Point of View. Balance Responsible Parties (BRPs). Available online: https:/ / www.emissions-euets.com/balance-responsible-parties-brp (accessed on 26 May 2021).

33. IRENA. Innovation Landscape Brief: Aggregators; International Renewable Energy Agency: Abu Dhabi, United Arab Emirates, 2019.

34. Abreu, C.; Rua, D.; Machado, P.; Peças Lopes, J.A.; Heleno, M. Advanced Energy Management for Demand Response and Microgeneration Integration. In Proceedings of the 2018 Power Systems Computation Conference (PSCC), Dublin, Ireland, 11-15 June 2018; pp. 1-7. 
35. National Grid (UK). System Needs and Product Strategy, 2017. Available online: https://www.nationalgrideso.com/document /84261/download (accessed on 20 July 2021).

36. EU-SysFlex Consortium. EU-SysFlex: State-of-the-Art Literature Review of System Scarcities at High Levels of Renewable Generation (D2.1), 2018. Available online: http://eu-sysflex.com/wp-content/uploads/2018/12/D2.1_State-of-the-Art_Literat ure_Review_of_System_Scarcities_at_High_Levels_of_Renewable_Generation_V1.pdf (accessed on 20 July 2021).

37. Mercados, A.F.; E-Bridge; REF-E. Identification of Appropriate Generation and System Adequacy Standards for the Internal Electricity Market; European Commission: Luxembourg, 2014.

38. Migliavacca, G. TSO-DSO Interactions and Ancillary Services in Electricity Transmission and Distribution Networks Modeling, Analysis and Case-Studies: Modeling, Analysis and Case-Studies; Springer Nature Switzerland AG: Cham, Switzerland, 2020; ISBN 978-3-030-29202-7.

39. ENTSO-E. Electricity Balancing in Europe, 2018. Available online: https:/ / eepublicdownloads.entsoe.eu/clean-documents/Network\% 20codes\%20documents/NC\%20EB/entso-e_balancing_in\%20_europe_report_Nov2018_web.pdf (accessed on 20 July 2021).

40. California ISO. Flexible Ramping Product-Revised Draft Final Proposal, 2015. Available online: https://web.archive.org/web/20 201028195004/https:/ / www.caiso.com/Documents/RevisedDraftFinalProposal-FlexibleRampingProduct-2015.pdf (accessed on 20 July 2021).

41. Navid, N.; Rosenwald, G. Ramp Capability Product Design for MISO Markets, 2013. Available online: https:/ / cdn.misoenergy .org/Ramp\%20Capability\%20for\%20Load\%20Following\%20in\%20MISO\%20Markets\%20White\%20Paper271169.pdf (accessed on 20 July 2021).

42. ENWL. Architecture of Tools for Load Scenarios (ATLAS). Available online: https://www.enwl.co.uk/go-net-zero/innovation/smal ler-projects/network-innovation-allowance/enw1008---architecture-of-tools-for-load-scenarios-atlas/ (accessed on 26 May 2021).

43. Coordinet Consortium Coordinet. Available online: https:/ / coordinet-project.eu (accessed on 26 May 2021).

44. Bne. Decentralized Flexibility Market2.0 A Market Based Solution for Organizing Access to Flexibility on the Local Distribution Network, 2016. Available online: https:/ / www.bne-online.de/fileadmin/bne/Dokumente/Englisch/Policy_Papers/201607 04_bne_De-Flex-Market_2.0_final.pdf (accessed on 20 July 2021).

45. EcoGrid EU Consortium. EcoGrid EU. Available online: http:/ / www.eu-ecogrid.net/ (accessed on 26 May 2021).

46. EMPOWER Consortium. Empower-Local Electricity Retail Markets for Prosumer Smart Grid Power Services. Available online: http: / / empowerh2020.eu/ (accessed on 26 May 2021).

47. USEF Foundation Enera-Usef Energy. Available online: https://www.usef.energy/implementations/enera/ (accessed on 26 May 2021).

48. Zhang, C.; Ding, Y.; Nordentoft, N.C.; Pinson, P.; Østergaard, J. FLECH: A Danish Market Solution for DSO Congestion Management through DER Flexibility Services. J. Mod. Power Syst. Clean Energy 2014, 2, 126-133. [CrossRef]

49. Esmat, A.; Usaola, J.; Moreno, M.Á. Distribution-Level Flexibility Market for Congestion Management. Energies 2018, 11, 1056. [CrossRef]

50. EU-SysFlex Consortium. EU-SysFlex. Available online: https://eu-sysflex.com/ (accessed on 8 March 2021).

51. FLEXICIENCY Consortium. Energy Services Demonstrations of Demand Response, FLEXibility and Energy EffICIENCY Based on Metering Data. Available online: https:/ / cordis.europa.eu/project/id/646482 (accessed on 26 May 2021).

52. Spiliotis, K.; Gutierrez, A.I.R.; Belmans, R. Demand Flexibility versus Physical Network Expansions in Distribution Grids. Appl. Energy 2016, 182, 613-624. [CrossRef]

53. ENWL. Future Network Modelling Functions. Available online: https://www.enwl.co.uk/go-net-zero/innovation/smaller-proj ects/network-innovation-allowance/enwl016---future-network-modelling-functions / (accessed on 26 May 2021).

54. GOPACS members. GOPACS: The Grid Operators Platform That Helps Solve Congestion in the Electricity Grid. Available online: https: / / en.gopacs.eu/ (accessed on 26 May 2021).

55. InteGrid Consortium. InteGrid-Smart Grid Solutions. Available online: https://integrid-h2020.eu/ (accessed on 8 March 2021).

56. Interflex Consortium. Interflex-Local Use of Flexibilities for an Increasing Share of Renewables on the Distribution Grid. Available online: https:/ /interflex-h2020.com/ (accessed on 8 March 2021).

57. INTERRFACE Consortium. INTERRFACE. Available online: http://www.interrface.eu/ (accessed on 8 March 2021).

58. OMIE Proyecto IREMEL. Available online: https://www.omie.es/pt/proyecto-iremel (accessed on 8 March 2021).

59. NODES. NODES-European Marketplace for Decentralised Flexibility. Available online: https://nodesmarket.com/ (accessed on 8 March 2021).

60. Energy Networks Association. Open Networks: Developing the Smart Grid. Available online: https://www.energynetworks.org / creating-tomorrows-networks / open-networks (accessed on 8 March 2021).

61. Open Utility Ltd. Piclo-Building Software for a Smarter Energy Future. Available online: https://piclo.energy/ (accessed on 8 March 2021).

62. PlatOne Consortium. PLATform for Operation of Distribution Networks. Available online: https://cordis.europa.eu/project/id/ 864300 (accessed on 8 March 2021).

63. UK Power Networks. Power Potential. Available online: https://innovation.ukpowernetworks.co.uk/projects/power-potential/ (accessed on 8 March 2021).

64. SENSIBLE Consortium. Project SENSIBLE—Storage-Enabled Sustainable Energy for Buildings and Communities. Available online: https: / / www.projectsensible.eu/ (accessed on 8 March 2021). 
65. USEF Foundation. USEF. Available online: https://www.usef.energy/usef-foundation/ (accessed on 8 March 2021).

66. Shah, R.; Mithulananthan, N.; Bansal, R.C.; Ramachandaramurthy, V.K. A Review of Key Power System Stability Challenges for Large-Scale PV Integration. Renew. Sustain. Energy Rev. 2015, 41, 1423-1436. [CrossRef]

67. European Union Commission Regulation (EU) 2015/1222 of 24 July 2015 Establishing a Guideline on Capacity Allocation and Congestion Management, 2015. Available online: https:/ / eur-lex.europa.eu/legal-content/EN/TXT/?uri=CELEX\%3A32015R12 22 (accessed on 20 July 2021).

68. CENELEC. Standard EN 50160-Voltage Characteristics in Public Distribution Systems, 2010. Available online: https: / / www.se.com/ww/library/SCHNEIDER_ELECTRIC/SE_LOCAL/APS/204836_1312/DraftStandard0026rev2-DraftEN501 602005-05.pdf (accessed on 20 July 2021).

69. Yang, Y.; Enjeti, P.; Blaabjerg, F.; Wang, H. Wide-Scale Adoption of Photovoltaic Energy: Grid Code Modifications Are Explored in the Distribution Grid. IEEE Ind. Appl. Mag. 2015, 21, 21-31. [CrossRef]

70. Jahangiri, P.; Aliprantis, D. Distributed Volt/VAr Control by PV Inverters. In Proceedings of the 2014 IEEE PES General Meeting I Conference Exposition, Prince George's County, MD, USA, 27-31 July 2014; pp. 3429-3439.

71. Madureira, A.; Lopes, J.A. Coordinated Voltage Support in Distribution Networks with Distributed Generation and Microgrids. IET Renew. Power Gener. 2009, 3, 439. [CrossRef]

72. Rodrigues, J.; Lopes, A.; Miranda, L.; Gouveia, C.; Moreira, C.; Peças Lopes, J. The Role of Low-Voltage-Ride-Through Capability of Distributed Energy Resources for the Mitigation of Voltage Sags in Low Voltage Distribution Grids. In Proceedings of the 2018 Power Systems Computation Conference (PSCC), Dublin, Ireland, 11-15 June 2018; pp. 1-7.

73. IEEE Power \& Energy Society Industry Technical Support Leadership Committee. Technical Report PESTR83. Resilience Framework, Methods, and Metrics for the Electricity Sector, 2020. Available online: https:// resourcecenter.ieee-pes.org/publicat ions/technical-reports/PES_TP_TR83_ITSLC_102920.html (accessed on 20 July 2021).

74. Lopes, J.A.P.; Moreira, C.L.; Madureira, A.G. Defining Control Strategies for MicroGrids Islanded Operation. IEEE Trans. Power Syst. 2006, 21, 916-924. [CrossRef]

75. Moreira, C.L.; Resende, F.O.; Lopes, J.A.P. Using Low Voltage MicroGrids for Service Restoration. IEEE Trans. Power Syst. 2007, 22, 395-403. [CrossRef]

76. Reis, M.; Garcia, A.; Bessa, R.; Seca, L.; Gouveia, C.; Moreira, J.; Nunes, P.; Matos, P.G.; Carvalho, F.; Carvalho, P. Predictive Management of Low-Voltage Grids. CIRED Open Access Proc. J. 2017, 2017, 1935-1939. [CrossRef]

77. Klyapovskiy, S.; You, S.; Cai, H.; Bindner, H.W. Incorporate Flexibility in Distribution Grid Planning through a Framework Solution. Int. J. Electr. Power Energy Syst. 2019, 111, 66-78. [CrossRef]

78. Manson, S.; McCullough, E. Practical Microgrid Protection Solutions: Promises and Challenges. IEEE Power Energy Mag. 2021, 19, 58-69. [CrossRef]

79. Moreno, R.; Panteli, M.; Mancarella, P.; Rudnick, H.; Lagos, T.; Navarro, A.; Ordonez, F.; Araneda, J.C. From Reliability to Resilience: Planning the Grid Against the Extremes. IEEE Power Energy Mag. 2020, 18, 41-53. [CrossRef]

80. Zhou, Y.; Panteli, M.; Moreno, R.; Mancarella, P. System-Level Assessment of Reliability and Resilience Provision from Microgrids. Appl. Energy 2018, 230, 374-392. [CrossRef]

81. Gerard, H.; Rivero, E.; Six, D. SmartNet Project-Basic Schemes for TSO-DSO Coordination and Ancillary Services Provision (D1.3), 2016. Available online: http://smartnet-project.eu/wp-content/uploads/2016/12/D1.3_20161202_V1.0.pdf (accessed on 20 July 2021).

82. Rossi, M.; Migliavacca, G.; Viganò, G.; Siface, D.; Madina, C.; Gomez, I.; Kockar, I.; Morch, A. TSO-DSO Coordination to Acquire Services from Distribution Grids: Simulations, Cost-Benefit Analysis and Regulatory Conclusions from the SmartNet Project. Electr. Power Syst. Res. 2020, 189, 106700. [CrossRef]

83. Gerard, H.; Rivero Puente, E.I.; Six, D. Coordination between Transmission and Distribution System Operators in the Electricity Sector: A Conceptual Framework. Util. Policy 2018, 50, 40-48. [CrossRef]

84. TDX-ASSIST consortium. TDX-ASSIST Website. Available online: http:/ / www.tdx-assist.eu/ (accessed on 28 June 2021).

85. TDX-ASSIST consortium. D4.1 Exchange Evaluations, 2020. Available online: https://ec.europa.eu/research/participants/doc uments /downloadPublic?documentIds=080166e5cbb87ba0\&appId=PPGMS (accessed on 20 July 2021).

86. CEDEC.; E.DSO.; EURELECTRIC.; GEODE. Smart Grid Key Performance Indicators: A DSO Perspective, 2021. Available online: https://cdn.eurelectric.org/media/5272/smart_grid_key_performance_indicators_a_dso_perspective-2021-030-012901-e-h-B85F16BF.pdf (accessed on 20 July 2021).

87. Energy Networks Australia. Open Energy Networks Project: Energy Networks Australia Position Paper, 2020. Available online: https://www.energynetworks.com.au/resources/reports/2020-reports-and-publications/open-energy-networks-pro ject-energy-networks-australia-position-paper/ (accessed on 20 July 2021).

88. AEMO; Energy Networks Australia. Interim Report: Required Capabilities and Recommended Actions, 2019. Available online: https://www.energynetworks.com.au/assets/uploads/open_energy_networks_-_required_capabilities_and_recomm ended_actions_report_22_july_2019.pdf (accessed on 20 July 2021).

89. Alexander, D.; Wyndham, J.; James, G.; McIntosh, L. Networks Renewed: Technical Analysis; Institute for Sustainable Futures, University of Technology Sydney: Sydney, Australia, 2017.

90. UTS. Networks Renewed: Project Results and Lessons Learnt; Institute for Sustainable Futures, University of Technology Sydney: Sydney, Australia, 2019. 
91. Voltus-Why Voltus? Available online: https://www.voltus.co/why-voltus/ (accessed on 20 July 2021).

92. PJM Reserve Market. Available online: https://www.pjm.com/Globals/Training/Courses/ol-reserve-market (accessed on 20 July 2021).

93. NYISO. The State of Storage: Energy Storage Resources in NY Wholesale Electricity Markets, 2017. Available online: https://ww w.nyiso.com/documents / 20142/2225293/2017-State-Of-Storage-Report.pdf/c80da6ff-b239-3464-3b6d-f191bf62c597 (accessed on 20 July 2021).

94. Boemer, J.; Lannoye, E. Transmission and Distribution Operations and Planning Coordination - TSO/DSO and Tx/Dx Planning Interaction, Processes, and Data Exchange, 2019. Available online: https://www.epri.com/research/products/000000003002016 712 (accessed on 20 July 2021).

95. MISO. Load Modifying Resources: 'Soup to Nuts', 2019. Available online: https://cdn.misoenergy.org/20191008\%20LMR\%20Ov erview\%20Presentation389597.pdf (accessed on 20 July 2021).

96. Load Shed Service for Imports. Available online: https://www.aeso.ca/market/ancillary-services/load-shed-service-for-import s/ (accessed on 1 July 2021).

97. King, J.; Kirby, B.; Milligan, M.; Beuning, S. Flexibility Reserve Reductions from an Energy Imbalance Market with High Levels of Wind Energy in the Western Interconnection; National Renewable Energy Lab. (NREL): Golden, CO, USA, 2011.

98. Stimatz, J. Western Energy Imbalance Market Update, 2020. Available online: https://leg.mt.gov/content/Committees/Interim/ 2019-2020/Energy-and-Telecommunications/Meetings/July-2020/Stimatz-PowerPoint.pdf (accessed on 20 July 2021). 